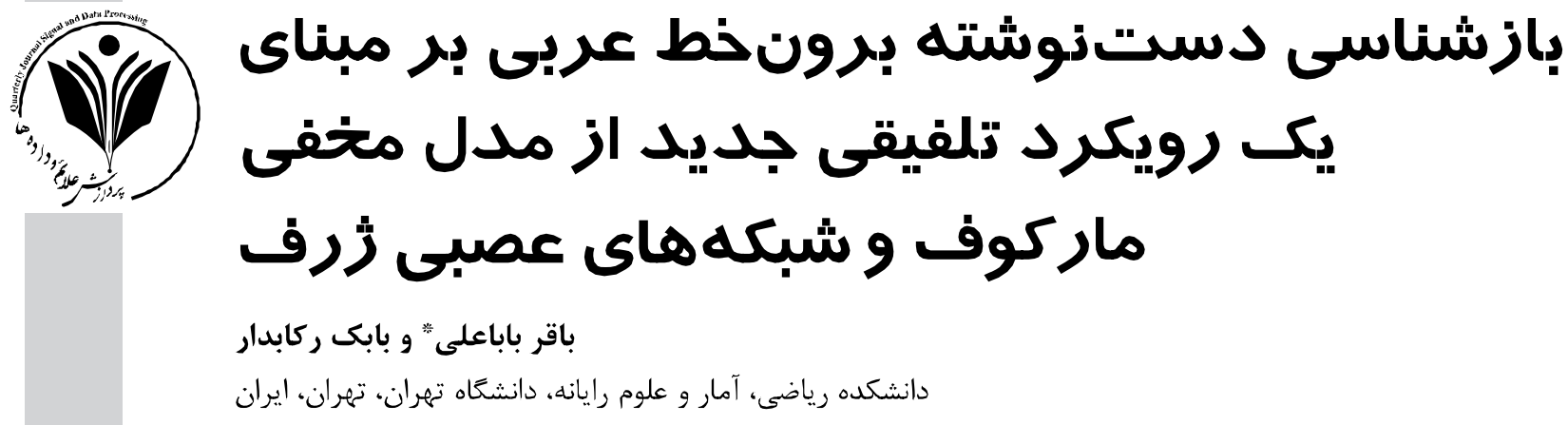

جكکبه

مسأله مدل سازى و بازشناسى دستنوشته شباهت بسيار زيادى به مسأله مدل سازى و بازشناسى تكفتار دارد. به همين علت مى توان از

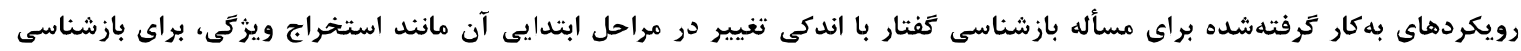
دستنوشته نيز بهره برد. با كسترش رويكردهاى تركيبى HMM-DNN و استفاده از توابع هدف دون دنبالهاى مانند

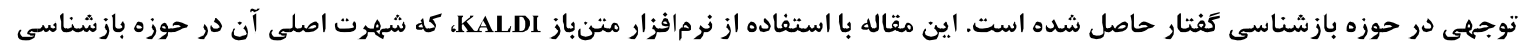

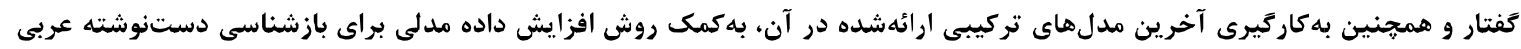

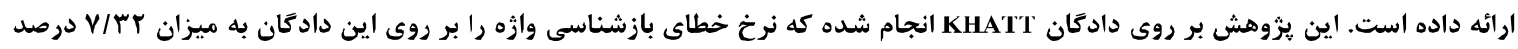
مطلق كاهش داده است.

KALDI وازًان كليدى: بازشناسى دستنوشته عربى، شبكههاى عصبى ثرف، مدل مخفى ماركوف، نرمافزار متنباز

\title{
Off-line Arabic Handwritten Recognition Using a Novel Hybrid HMM-DNN Model
}

\author{
Bagher BabaAli* \& Babak Rekabdar \\ School of Mathematics, Statistics and Computer Sciences, College of Science, University of \\ Tehran, Tehran, Iran
}

\begin{abstract}
In order to facilitate the entry of data into the computer and its digitalization, automatic recognition of printed texts and manuscripts is one of the considerable aid to many applications. Research on automatic document recognition started decades ago with the recognition of isolated digits and letters, and today, due to advancements in machine learning methods, efforts are being made to identify a sequence of handwritten words. Generally, based on the type of text, document recognition is divided into two main categories: printed and handwritten. Due to the limited number of fonts relative to the diversity of handwriting of different writers, it is much easier to recognize printed texts than handwritten text; thus, the technology of recognizing printed texts has matured and has been marketed in the form of a product. Handwritting recognition task is usually done in two ways: online and offline; offline handwriting recognition involves the automated translation of text in image format to letters that can be used in computer and text-processing applications. Most of the research in the field of handwriting recognition has been conducted on Latin script, and a variety of tools and resources have been gathered for this script. This article focuses on the application of the latest methods in the field of speech recognition for the recognition of Arabic handwriting. The task of handwritten text modeling and recognizing is very similar to the task of speech modeling and recognition. For this reason, it is possible to apply the approaches used for the speech recognition with a slight change for the handwriting recognition. With the expansion of HMM-DNN hybrid approaches and

* Corresponding author

* نويسنده عهدهدار مكاتبات
\end{abstract}

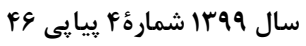

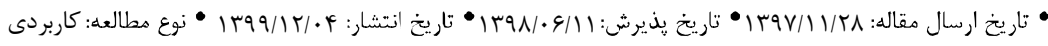


the use of sequential objective functions such as MMI, significant improvements have been made in the accuracy of speech recognition system. This paper presents a pipeline for the offline Arabic handwritten text recognition using the open source KALDI toolkit, which is very well-known in the community of speech recognition, as well as the use of the latest hybrid models presented in it and data augmentation techniques. This research has been conducted on the Arabic KHATT database, which achieved $7.32 \%$ absolute reduction in word recognition error (WER) rate.

Keywords: Arabic Handwritten Recognition, Deep Neural Networks, Hidden Markov Model, Kaldi Toolkit

باشد كه در اين صورت، بهطورمعمول لازم است در ابتدا قطعبندى خطوط تكتك خطوط بهطور مجزا صورت گيرد. كيفيت تصاوير حاصل از بويش دستنوشتهها، تنوع بسيار بالاى دستنوشته افراد مختلف، فاصلهoاى ايجادشده بين كلمات و يا حتى بخشهايى از يك كلمه و همجنين تنوع در اندازه و نوع قلم را مىتوان از جمله عواملى دانست كه بازشناسى دستنوشته

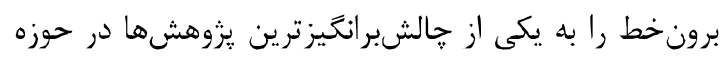
تحليل و بازشناسى متون تبديل كرده است. ئل

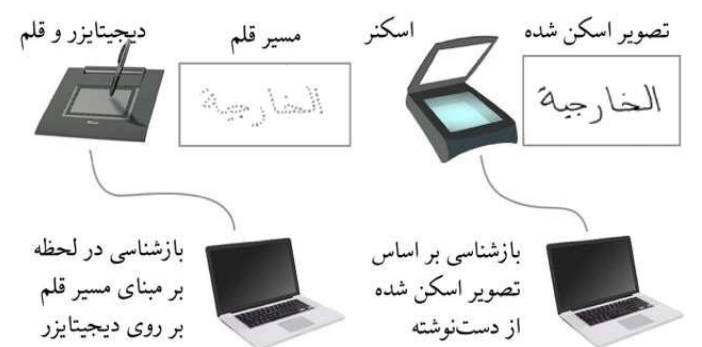

(شكل -1): بازشناسى دستنوشته به دو صورت برخط و برون خط (Figure-1): Offline and online handwritten recognition

خطوط نكارشى زنده و متداول در دنيا شامل لاتين،

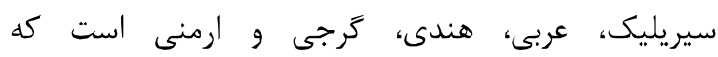

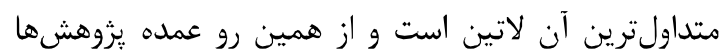

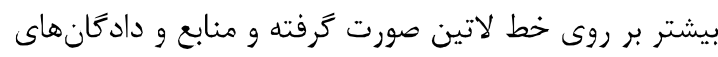
متعددى در اين زمينه كردآورى شده است. در در اين بين بين، يثوهشهاى بلمراتب كمترى بر روى دستنوشته عربى و

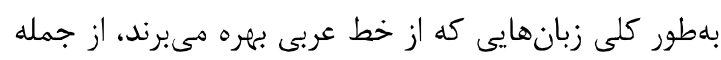

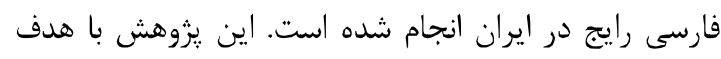

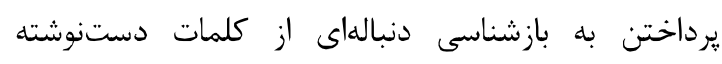
ييوسته فارسى بر مبناى رويكردها و روشهاى نوين ارائهشده در ساليان اخير آغاز شد، ولى بلددليل عدم وجود يك دادكان دستنوشته فارسى مناسب براى انجام آزمايشها و همجنين

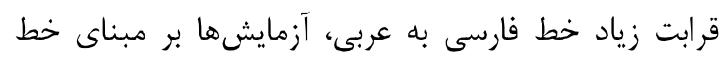
عربى و بهطور مشخص دادكان KHATT انجام شد.

${ }^{6}$ Line Segmentation
- 1 در راستاى تسهيل ورود اطلاعات به رايانه و ديجيتالسازى

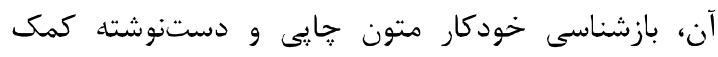

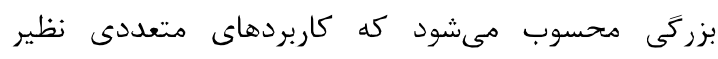

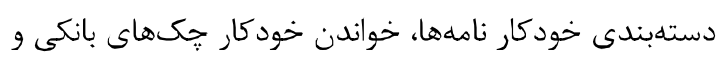

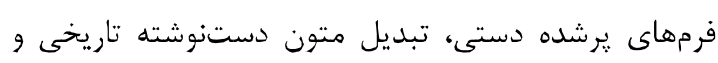

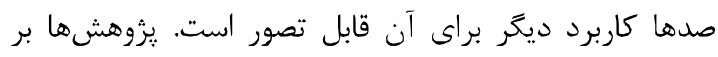

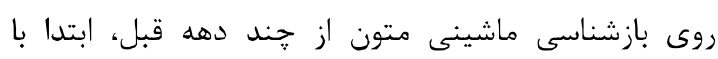

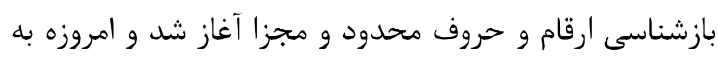

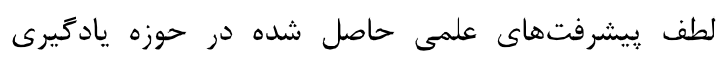

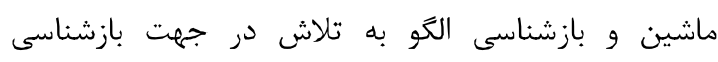
دنبالهاى از كلمات دستنوشته ييوسته منجر شده است.

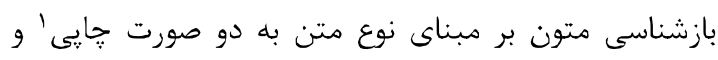

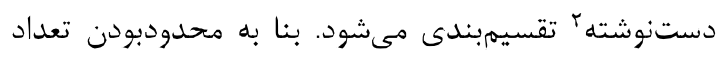

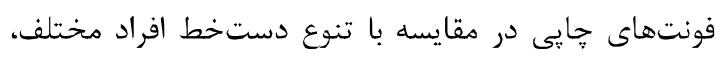

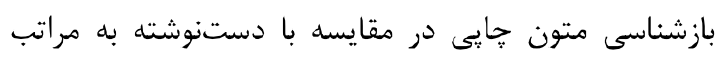

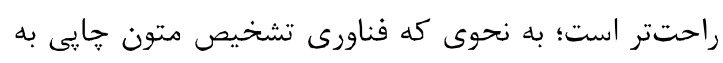
بلوغ رسيده و در قالب محصول به بازار عرضه شده است.

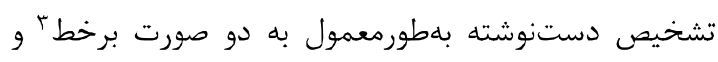

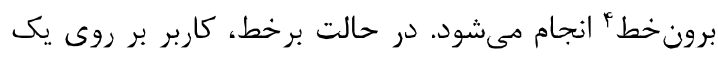

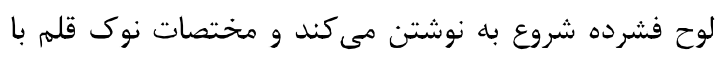

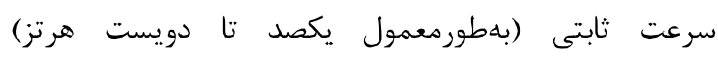

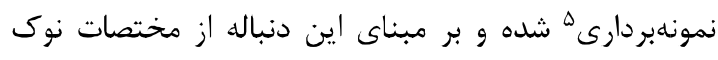

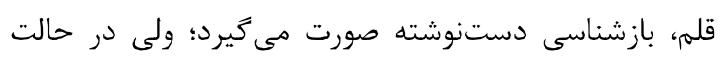

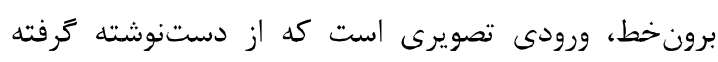

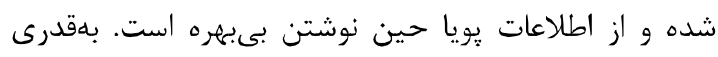
اين اطلاعات يويا در بهبود دقت بازشناسى مؤثر است كه در

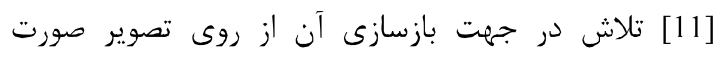

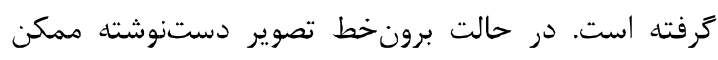
است شامل خطوط متعددى (بهعنوان مثال يك ياراكراف)

${ }^{1}$ Printed

${ }^{2}$ Handwritten

${ }^{3}$ Online

${ }^{4}$ Offline

${ }^{5}$ Sampling 
اين منظور بسيار محدود است. كمبود دادمًان مناسب باعث

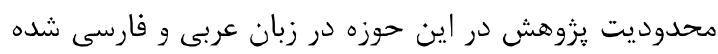

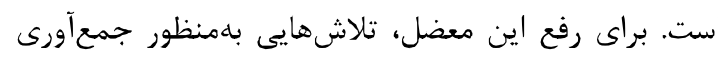

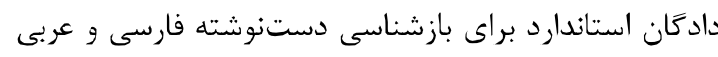

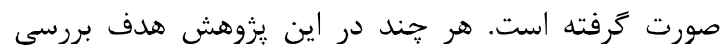

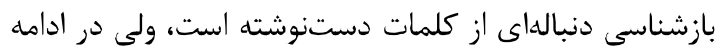

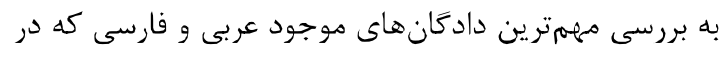

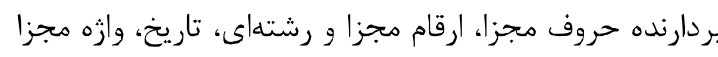

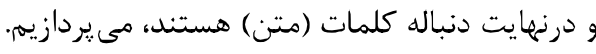
يكى از آخرين تلاشها براى جمعآورى دادئ دادمان

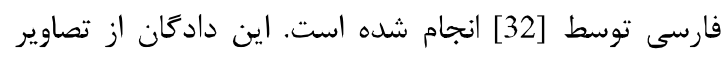

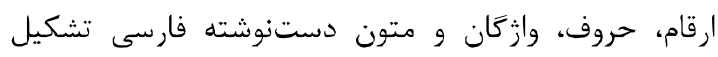

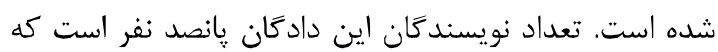

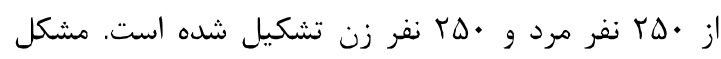

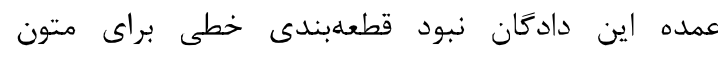

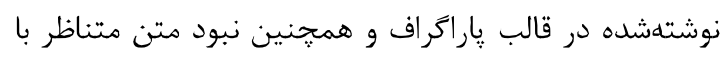

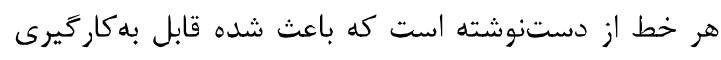
در يزوهش جارى نباشد.

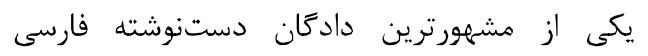

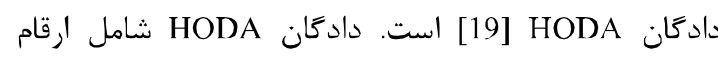

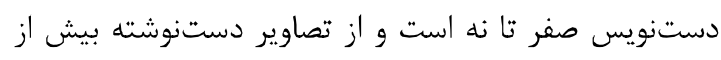

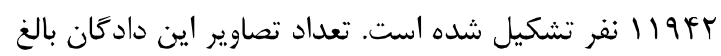

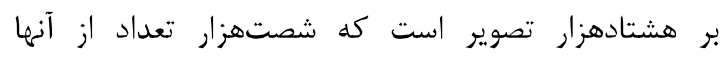

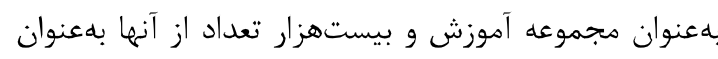

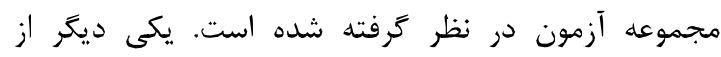

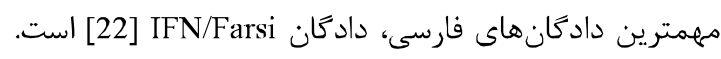
اين دادكان از تصاوير اسامى شهرها و و روستاهاى دانى ايران

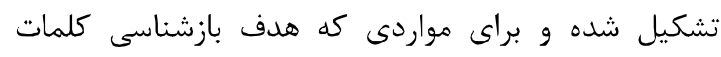

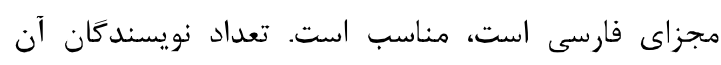

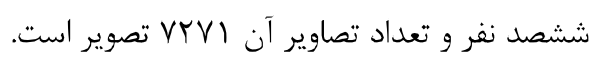

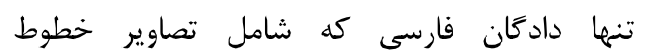

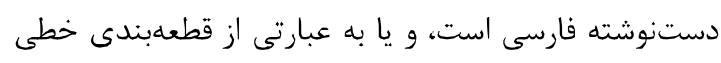

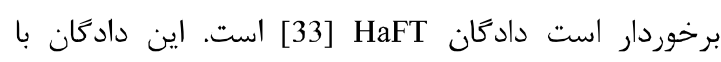
همكارى ششصد نويسنده تهيه شده است. هر نويسنده، سه اسه

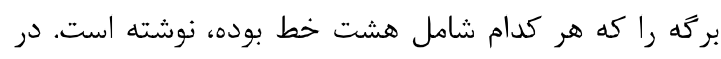

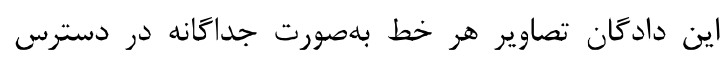

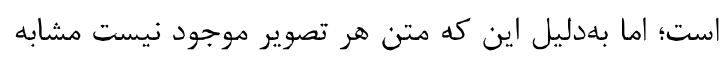

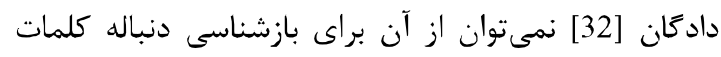
دستنوشته يِيوسته فارسى كد هدف اين مقاله است، برانهره
در ادامه اين مقاله، در بخش بعد به مرورى اجمالى بر

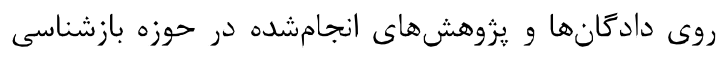

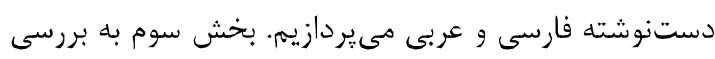

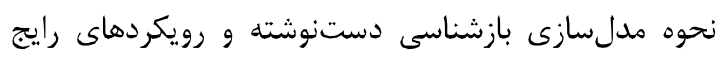

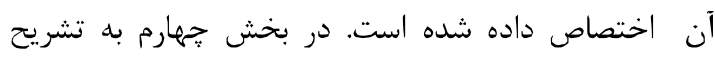

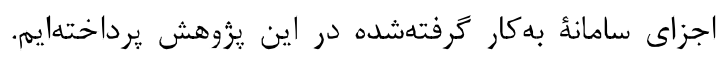

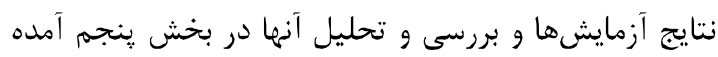
و درنهايت در بخش ششم جمعبندى ارائه شده است.

\section{r- مرور اجمالى دادَان ها و يثوهشها}

غالب يزوهشهاى انجامشده در حوزه بازشناسى دستنوشته

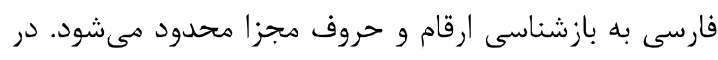

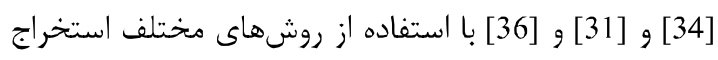
ويزگى و همجنين بهره

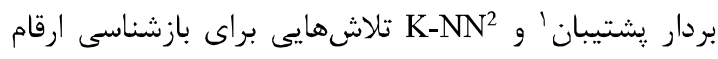

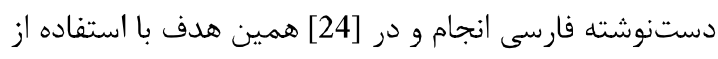

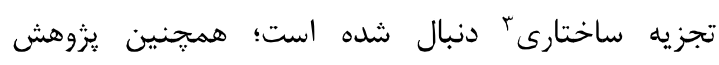

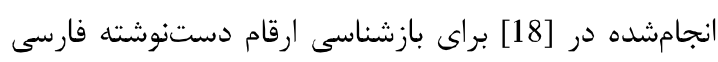

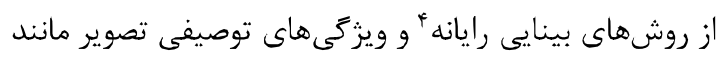
HOG

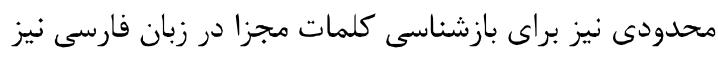

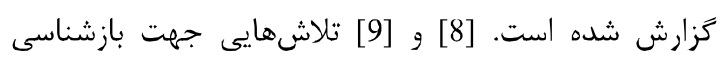

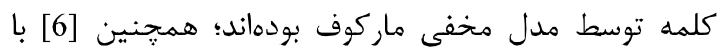

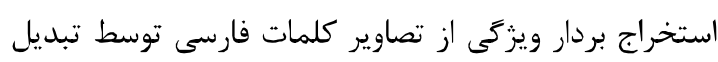

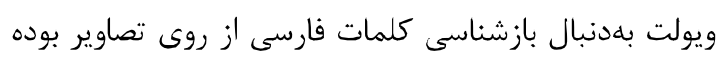

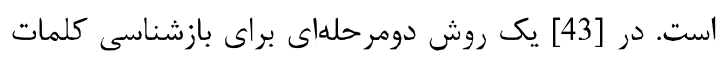

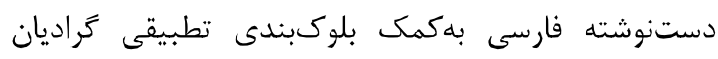
تصوير ارائه شده است. درهميناواخر نيز [30] از شبكهنهاى

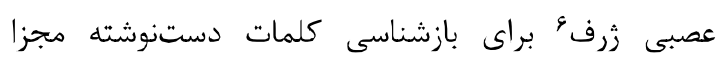

$$
\text { استفاده كرده است. }
$$

تا جايى كه مطلعايم، هيج يخوهشى روى بازشناسى

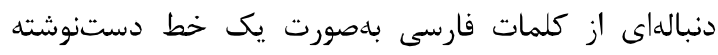

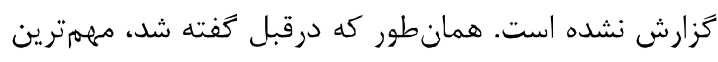

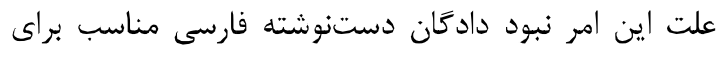

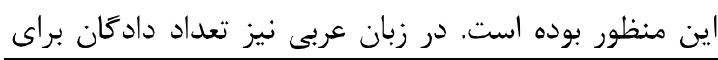

${ }^{1}$ Support Vector Machine

${ }^{2} \mathrm{~K}$-Nearest neighbor

${ }^{3}$ Structural Decomposition

${ }^{4}$ Computer Vision

${ }^{5}$ Histogram of Oriented Gradients

${ }^{6}$ Decp Neural Network 
دادكان براى مسائل ديخَىى مانند تشخيص نويسنده نيز بهره

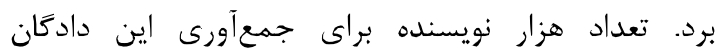

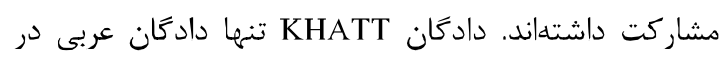
دسترس است كه برخلاف دو دادFان فارسى موجود، هم

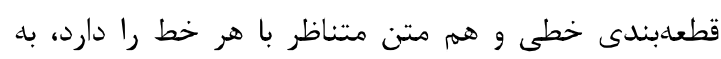

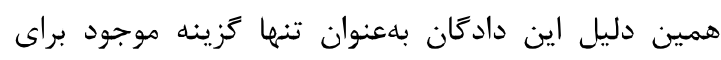
انجام آزمايشهاى اين يزوهش انتخاب شد. تعداد بيشترى از

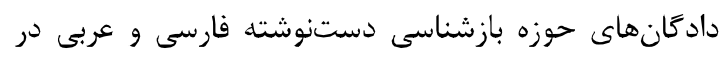

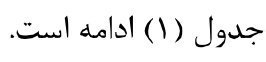

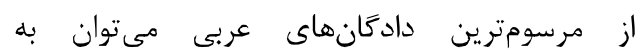

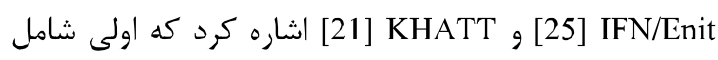
كلمات دجزا و دومى تصاوير خطوط دستهنوشته است كه هر

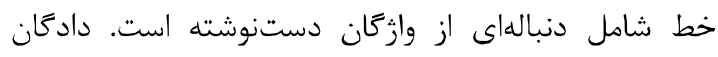
IFN/Enit شامل IFY شهر و روستا در كشور تونس تهيه شده است. تعداد

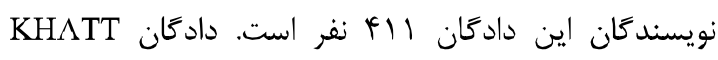

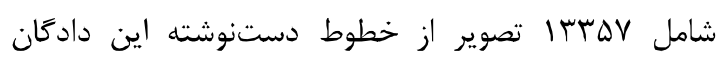

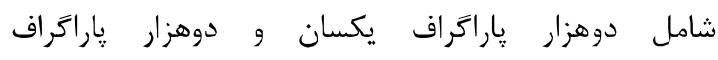

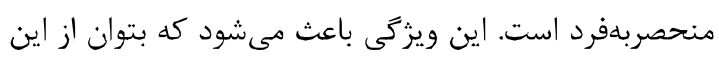

\begin{tabular}{|c|c|c|c|c|}
\hline نام دادَّان & 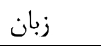 & 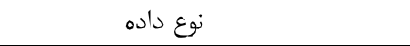 & تعداد نويسنده & تعداد تصاوير \\
\hline Sadri2016 [32] & فارسى & ارقام، حروف، كلمات و متون دستنوشته & 500 & 250624 \\
\hline HODA [19] & فارسى & 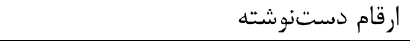 & 11942 & 80000 \\
\hline IFN/Farsi [22] & فارسى & اسامى شهرها و روستاهاى ايران & 600 & 7271 \\
\hline HaFT [33] & 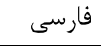 & يك خط دستنوشته & 600 & 14400 \\
\hline FHT [42] & 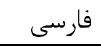 & ياراكراف دستنوشته & 250 & 1000 \\
\hline IAUT/PIICN [5] & فارسى & اسامى شهرهاى ايران & 380 & 34200 \\
\hline IFHCDB [23] & 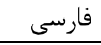 & حروف و ارقام دستنوشته & - & 70120 \\
\hline CENPARMI [15] & 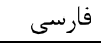 & ارقام، حروف، كلمات و متون دستنوشته & 295 & 41004 \\
\hline KHATT [21] & عربى & يك خط دستنوشته & 1000 & 13357 \\
\hline IFN/Enit [25] & 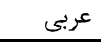 & اسامى شهرها و روستاهاى تونس & 411 & 26459 \\
\hline MADCAT Arabic [20] & 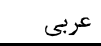 & يك خط دستنوشته & 305 & 750000 \\
\hline
\end{tabular}

\begin{tabular}{|c|c|}
\hline مدل سازى زبانى & مدل سازى زبانى \\
\hline مدل سازى طول شناسه & مدلسازى طول واج \\
\hline مدل سازى بافت شناسه & مدل سازى بافت واج \\
\hline تطبيق نويسنده & تطبيق كوينده \\
\hline
\end{tabular}

مشابه بازشناسى كَتار، در رويكرد آمارى بازشناسى

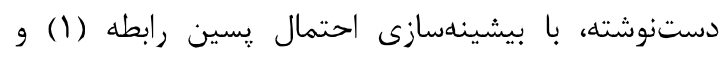
بهره بهازاى تصوير دستنوشته ورودى بهدست مئي آيد:

$W^{*}=\underset{W}{\operatorname{argmax}} P(W \mid X)=$

$$
\underset{W}{\operatorname{argmax}} P(X \mid W) P(W)
$$

كه

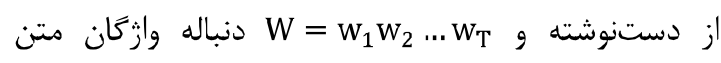
است. در اين رابطه P(X|W) مل مل ويزوال است كه توزيع احتمالى دستنوشته به شرط متن را تخمين مىزند و

\section{r- مدل سازى بازشناسى دستنوشته}

مسأله مدلسازى و بازشناسى دستنوشته شباهت بسيار

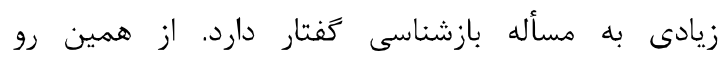
سامانهاى متنباز موجود در حوزه بازشناسى كفتار نظير [26] KALDI بازشناسى دستنوشته نيز بدكار زرفته شدهاند. اغلب ابتدا

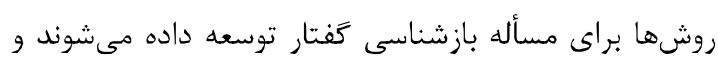
سيس براى حوزه بازشناسى دستنوشته اختصاصى مى شىند.

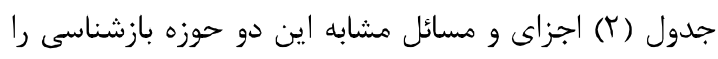
در هر سطر جدول ارائه داده است.

(جدول-r) : اجزاى و مسائل مشابه در بازشناسى كفتار و

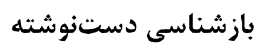

(Table-2): Similar issues in speech recognition and

\begin{tabular}{|c|c|}
\hline حوزه بازشناسى دستنوشته & حوزه بازشناسى تفتتار \\
\hline مدلسازى ويثوال & مدلسازى آكوستيك \\
\hline
\end{tabular}
handwritten recognition 


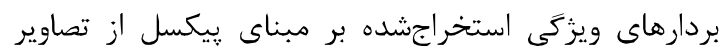

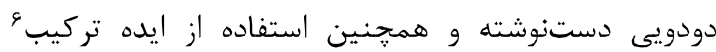
نتايج خروجى سه سامانه بازشناسى مبتنى بر HMM سامانه

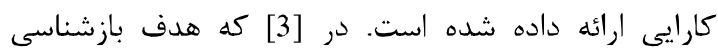
كلمات مجزا است دو نوع ويزگگى از تصوير وازه استخراج

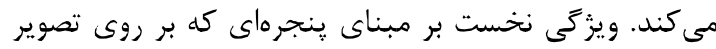

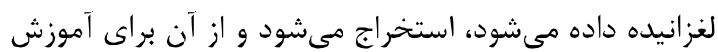

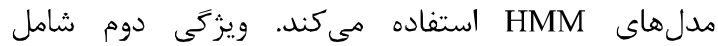

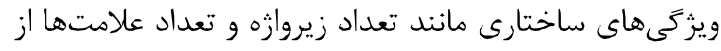
جمله نقطه است. در اين ساهانه ابتدا بازشناسى بلدوسيلة مدل هاى HMM انجام و در ادامه نتايج بهدست آمده بلوسيلئ ويزگى هاى ساختارى امتيازدهى مجدد لمى شيود. براى ساليان زيادى در عرصه بازشناسى دستنوشته

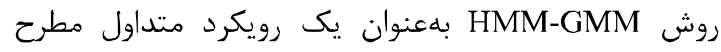
بوده است. با مطرحشدن يادكيرى زرف در ساليان اخير، رويكرد معروف به تركيبى كه مبتنى بر تلفيق مدل مخفى ماركوف با شبكههاى عصبى زرف (HMM-DNN) است، توانست از رويكرد متداول HMM-GMM بيشى بخيرد و نظر

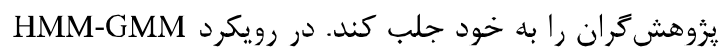

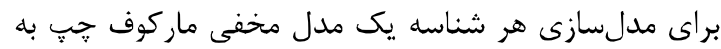

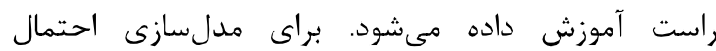

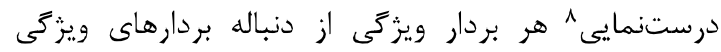

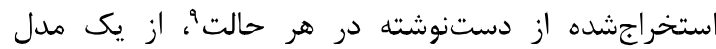

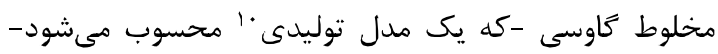

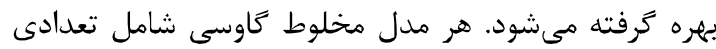

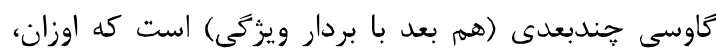

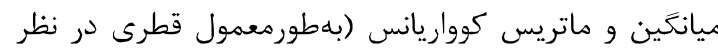

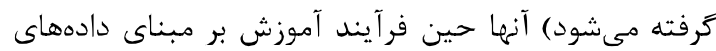
آموزشى مربوطه تخمين زده مى مئود.

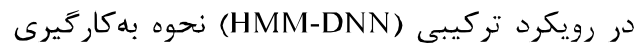

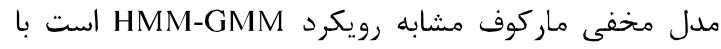

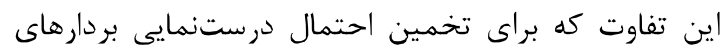
ويزگى در حالتها، يك شبكه عصبى - كه يك رئ روش

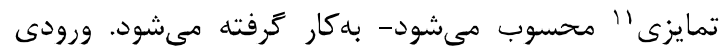

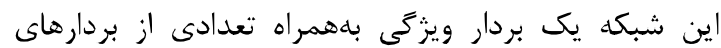
ويزگى مجاور آن (از هر دو طرف) و خروجى آن آن احتمال

${ }^{6}$ Fusion

${ }^{7}$ Rescoring

${ }^{8}$ Likelihood

${ }^{9}$ State

${ }^{10}$ Generative

11 Discriminative
مدل زبانى است كه احتمال رخداد دنباله وازگًان را

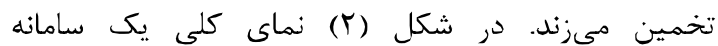
بازشناسى دستنوشته يِيوسته آمده است.

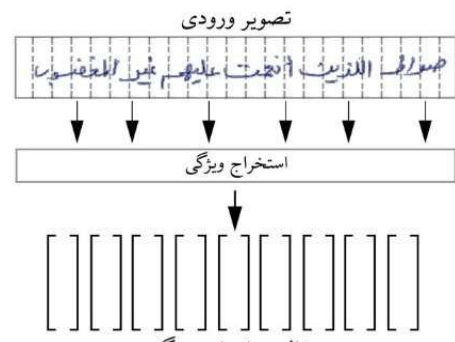

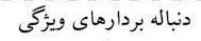

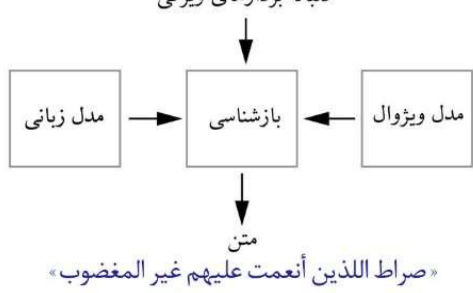

(شكل - ( ): نماى كلى از سامانه بازشناسى دستنوشته (Figure-2): Generic block diagram of the handwritten recognition systems

در مدلسازى ويثروال(P(X|W)، هدف برجسبزنى

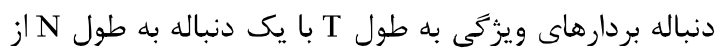

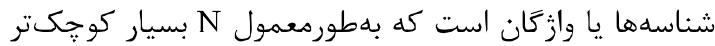

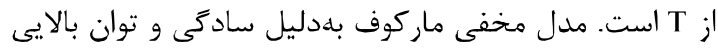
كه در مدلسازى الكوهاى متوالى' دارد، يكى از متداولت الترين روشهاى مدلسازى ويزوال محسوب مى شود. در اين روش،

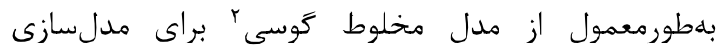

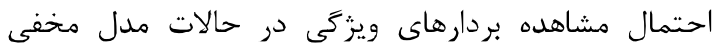

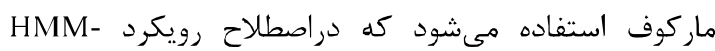
ناميده مى شود. از مههمرين يزوهشهايى كه با باستفادهاد از رويكرد HMM-GMM انجام شده است، مى توان به [16] اشاره كرد.

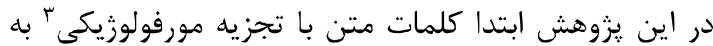

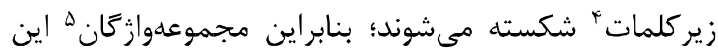
ساهانه تركيبى از كلمات و زيركلمات است كه اين سبب

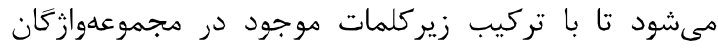

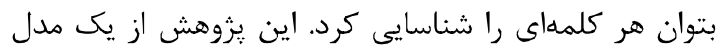
زبانى n-gram كه بر روى متن تجزيهشده آموزش داده شده

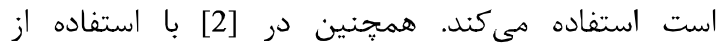

\footnotetext{
${ }^{1}$ Sequential Patterns

${ }^{2}$ Gaussian Mixture Model

${ }^{3}$ Morphological Decomposition

${ }^{4}$ Sub-word

${ }^{5}$ Lexicon
} 
وجود مجموعلوازكان در كنار مزيتى كه دارد يك عيب نيز

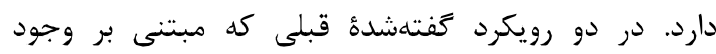

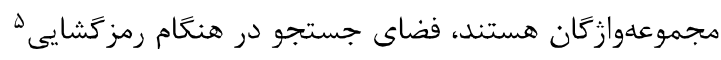

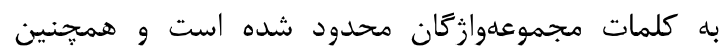

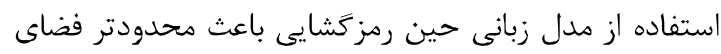

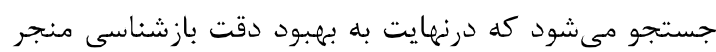
مىشود.

در سال VI ا.r يزوهش [1] از رويكرد انتهابهانتها بهمك روش CTC براى بازشناسى وازَّان بيوسته در زبان

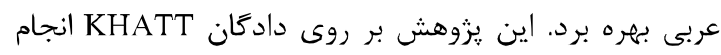

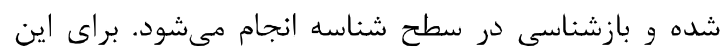

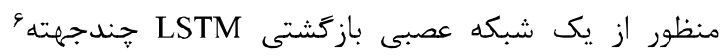

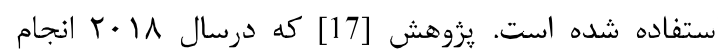

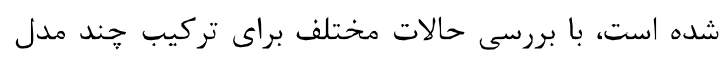

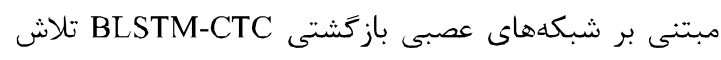

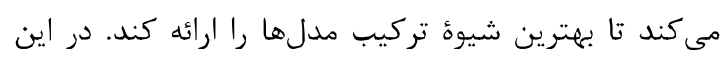

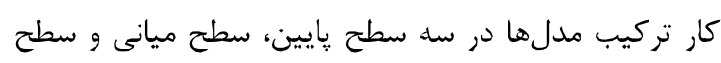

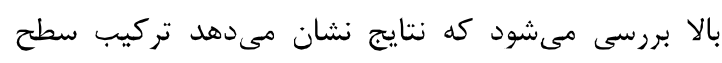

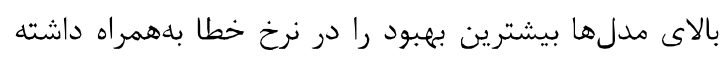

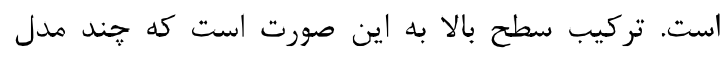

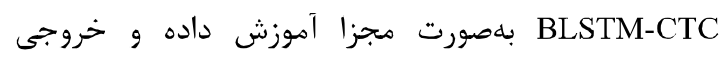
رمز كشايى همد آنها با هم تركيب مى مئشوند.

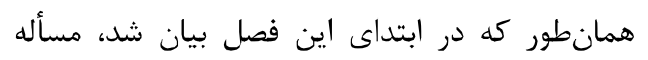

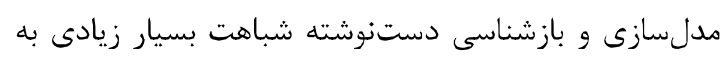

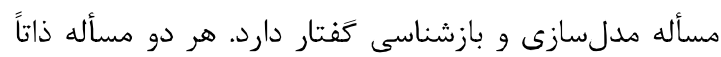

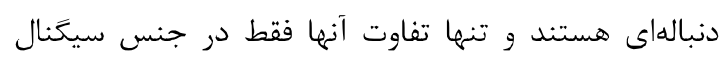

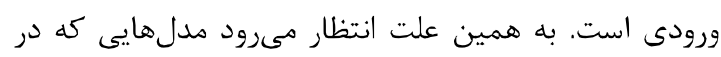

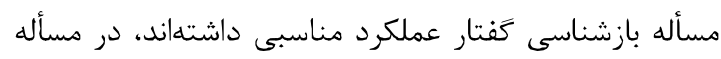

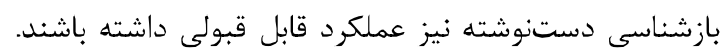

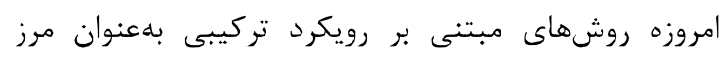

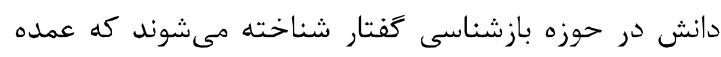

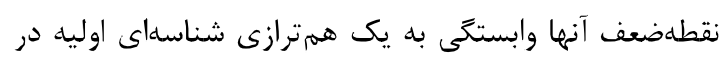

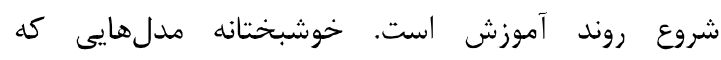

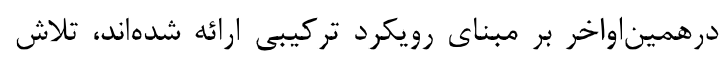

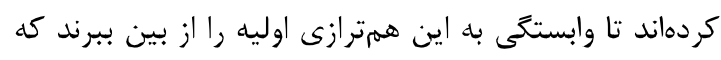

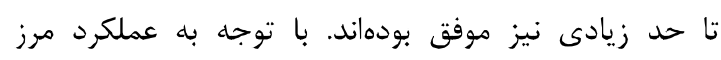

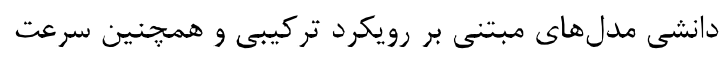

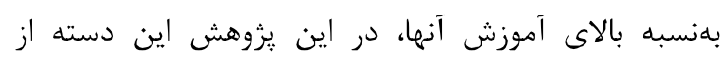
مدلها را براى مدلسازى انتخاب كردمايم.

${ }^{5}$ Decoding

${ }^{6}$ Multi-Directional Long-Short-Term-Memory
يسين است. تعداد نورونهاى خروجى شبكه برابر تعداد كل

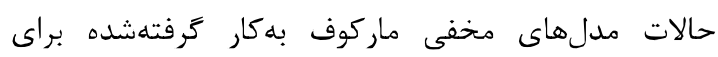

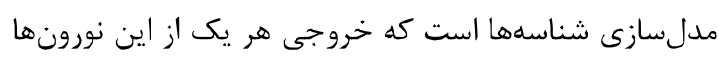

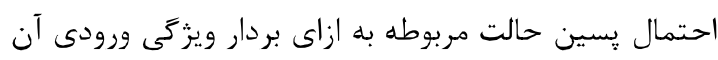

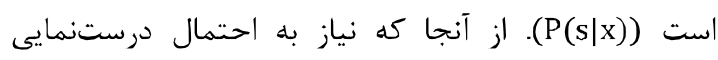

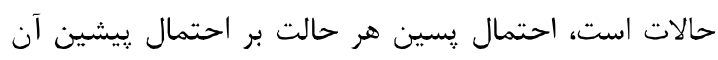

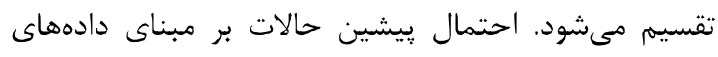

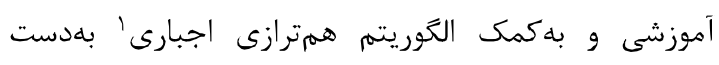

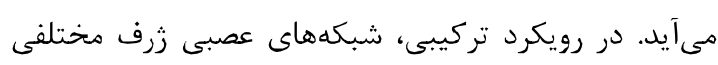

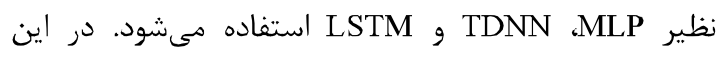

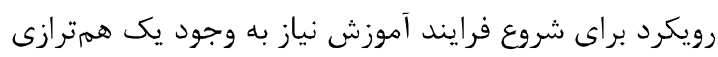

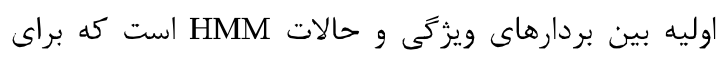

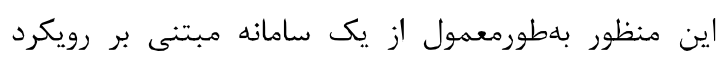

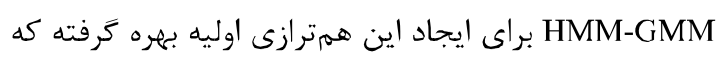

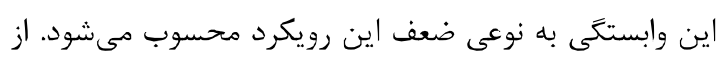

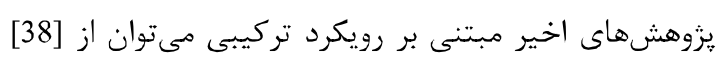

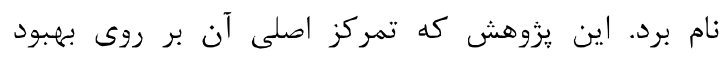

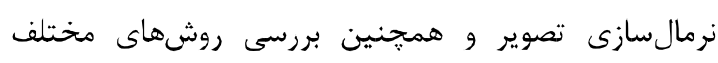

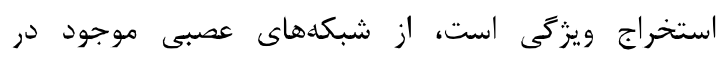

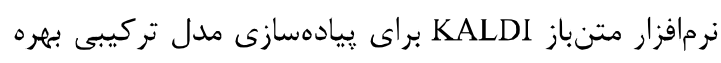

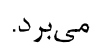

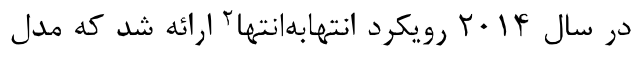

مخفى ماركوف بهطور كامل كنار كذاشته شده و از يك شبك شبكه

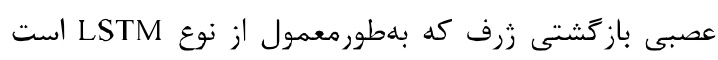

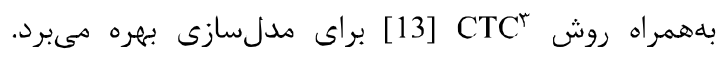

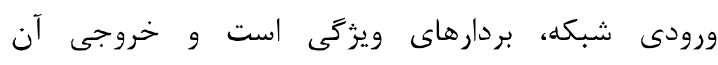

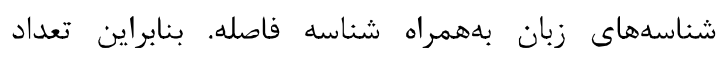

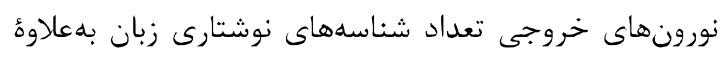

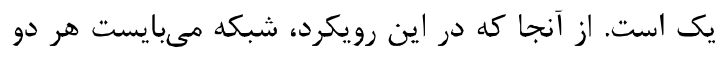

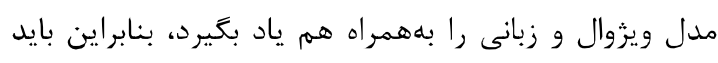

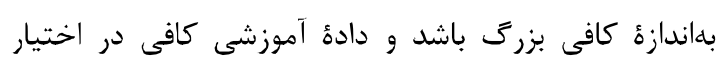

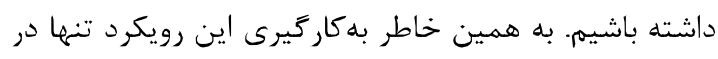

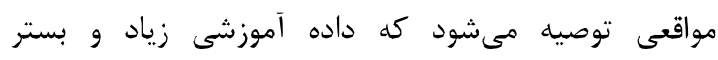

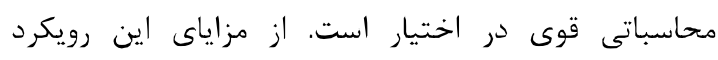

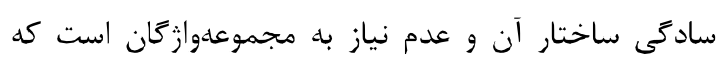

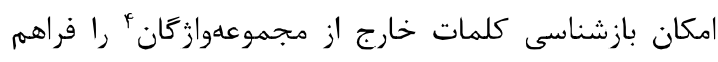

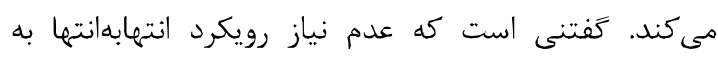

\footnotetext{
${ }^{1}$ Force Alignment

${ }^{2}$ End-to-End

${ }^{3}$ Connectionist Temporal Classification

${ }^{4}$ Out Of Vocabulary
} 
نرمالشدة كل خط بلدست آيد. اين كار كجى تصاوير خطوط را اصلاح مى كند.

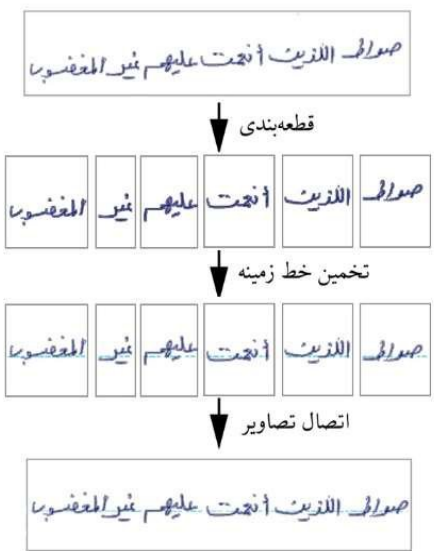

(شكل-f): مراحل تخمين و تصحيح خط زمينه

(Figure-4): Steps of baseline estimation and correction

يكى ديكر از ويزگىهاى تصاوير دستنوشتهاى

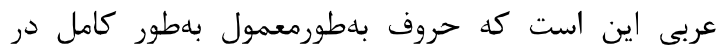

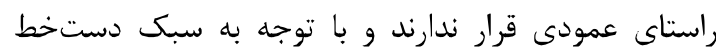
نويسنده قدرى به جٍِ و يا راست متمايل هستند. مرحله

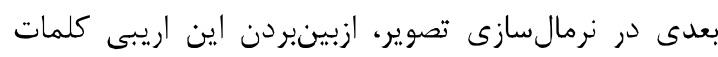

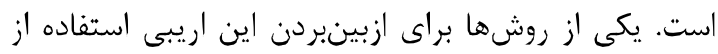

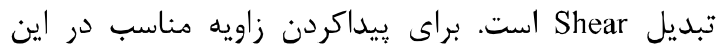

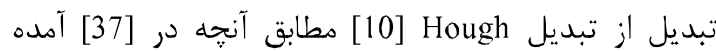

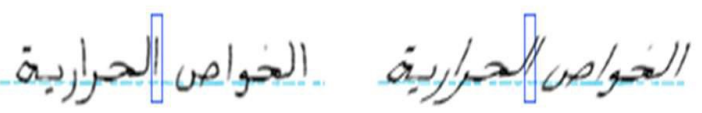

(شكل -ه): اريبى هاى متفاوت در دستنوشته فارسى

(Figure-5): Slants in Persian Handwritten

در اين يزوهش از ييكسلهاى خام تصوير بهعنوان

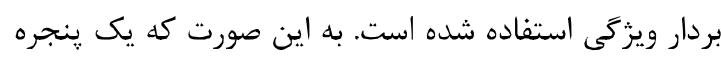

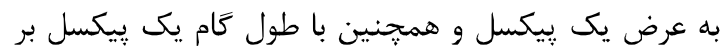

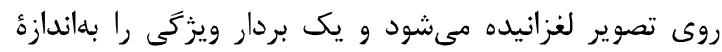
عرض تصوير كه مقادير خام بيكسلها هستند، توليد مى كند. به اين دليل كه ضرورى است، تعداد ويزگى هاى تمائ تمام

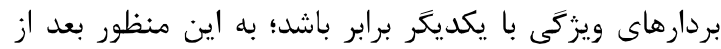

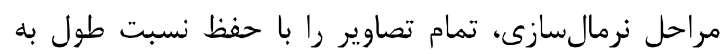
عرض آنها، به تصاويرى با عرض قينجاه بيكسل تغار تغيير اندازه مى دهيهم.
F - اجزاي سامانه

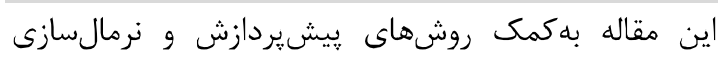

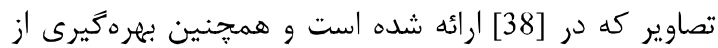
مدلسازىهاى بلهروز مبتنى بر رويكرد تركيبى، ساهانهاى را

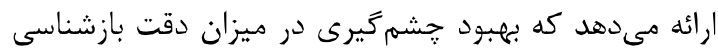
كلمات بر روى دادكان عربى KHATT را به همراه داشته

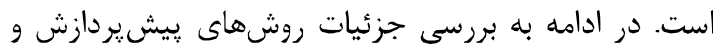
نرمالسازى تصاوير ورودى و روشهاى مدل رسازى تركيبى بهار كرفتهشده خواهيه يرداخت.

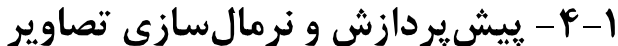

بيشيردازش و نرمالسازى تصاوير ورودى در حوزه

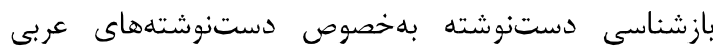
اهميت بالايى دارد. يزوهش [38] با تكيه بر نرمالسازى داسئ تصاوير قبل از آموزش مدل توانسته است بهبود قابل توجهى

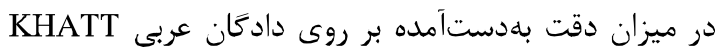

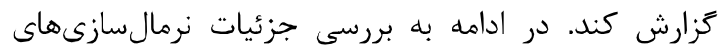

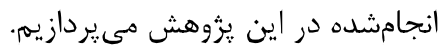
نخستين مرحله در نرمالسازى تصوير ورودى، تخمين

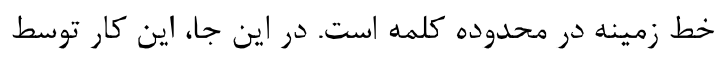
روشى كه در [37] ارائه شده است، انجام مى ديود. به اين صورت كه باريكترين نوارى كه بيشترين بخش از داز

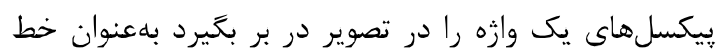

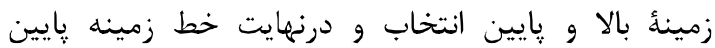
بهعنوان خط زمينه لحاظ مىشود.

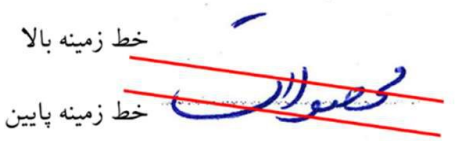

(شكل - "ا): تخمين خط زمينه بالا و یايين

(Figure-3): Upper and lower baseline estimation

براى تخمين خط زمينه يك خط دستنوشته، ابتدا

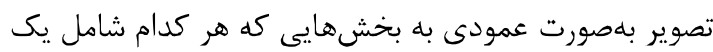

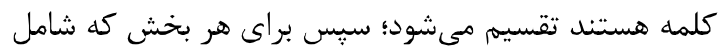
يك كلمه است به روش كفتهشده در بالا، خط زمينه تخمين زده مىشود. بعد از تخمين خط زمينه، تصوير را حول اين

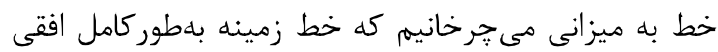
شود؛ سيس همه بخشها را به هم متصل مى كنيم تا تصوير 
بازشناسى كفتار به حساب مى آيد. روش LF-MMI در [14] بdنحوى تغيير داده شده است كه نياز به همترازى قبلى بلى ندارد. اين روش جديد LF-MMI تختآغاز

روش MMI در تئورى تفاوتى با روش LF-MMI

ندارد. محاسبه بر روى گراف مخرج در روش MMI مسأله

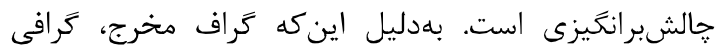

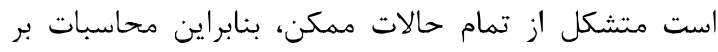
روى آن بسيار ير هزينه است؛ ازاينرو بهطورمعمول محاسبه

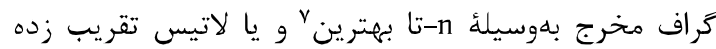
مىشود. به اين معنى كه به جاى محاسبه بر روى تمام

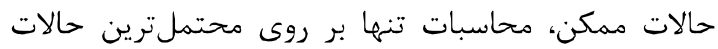
انجام مىشود. در روش MMI همجنين براى مقداردهى اوليه

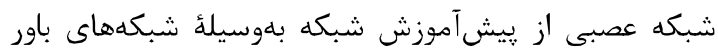
عميق ^ استفاده مىشود [7].

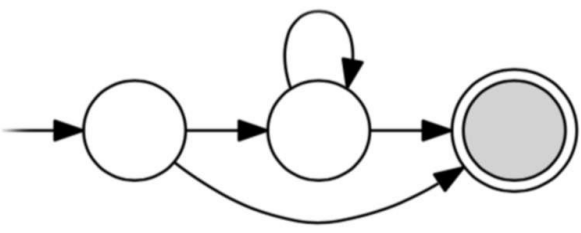

LF-MMI (شكل - (צ): تويولوزى شناسه در روش (Figure-6): HMM topology for characters in LF-MMI

تفاوت روش LF-MMI با روش آموزش تمايزى MMI

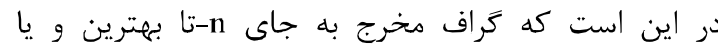
لاتيس بهصورت دقيق محاسبه و همجنين آموزش شبكه نيز با مقداردهى اوليه تصادفى شروع مىشود. براى كاهش هزينه محاسبات كراف مخرج سه روش بيشنهياد شده است:

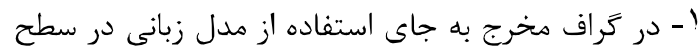
وازه، از مدل زبانى در سطح شناسه استفاده مى شيود. اين كار باعث مىشود اندازٔ كراف دو تا سه مرتبه كو ¥كتر شود.

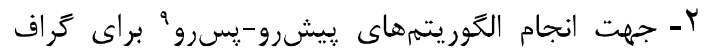

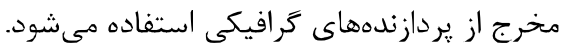

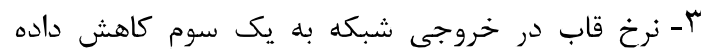

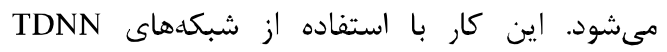
باسادگى قابل انجام است. اين كار باعث مىشود تا هم

${ }^{6}$ Flat start

${ }^{7} \mathrm{~N}$-best

${ }^{8}$ Deep Belief Network (DBN)

${ }^{9}$ Forward-Backward algorithms

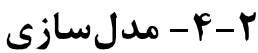

در روند آموزش مدلهاى مبتنى بر رويكرد تركيبى (IIMM-) كله هدف اين يزوهش است، مىتوان از توابع هدف (DNN مختلفى استفاده كرد. اين توابع هدف را ميىتوان به دو دسته توابع هدف در سطح قاب و توابع هدف در سطح دنباله تقسيم كرد. در مدلهايى كه توابع هدف آنها در سطح قاب تعريف شده است، بلروزرسانى ڤارامترهاى مدل بعد از مرده

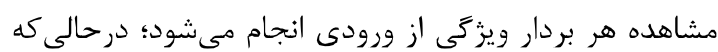
در مدلهايى كه توابع هدف آنها دنبالهاى است، ابتدا بايد

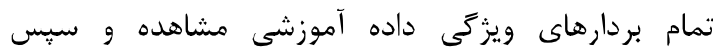

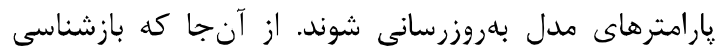
دستنوشته يك مسأله ذاتاً دنبالهاى است، انتظار مىرورد توابع هدف دنبالهاى عملكرد بهترى داشته باشند. از جمله مهمترين توابع دنبالهاى معرفىشده در حوزء بازشناسى كفتار كه مىتوان در بازشناسى دستنوشته نيز از آنها بهره [28] $\mathrm{MPE}^{4}, \mathrm{MWE}^{3}$ ،12] $\mathrm{sMBR}^{2}$ ،[4] $\mathrm{MMI}^{1}$ ، هستند كه شباهتهاى بسيار زيادى به يكديكر دارند.

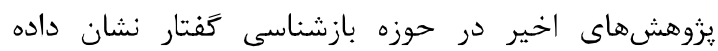

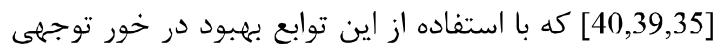
قابل حصول است كه انتظار مىرود بهكارگيريى آنها در بازشناسى دستنوشته نيز مؤثر واقع شود. يايه توابع هدف تمايزى بر مبناى بيشينهسازى

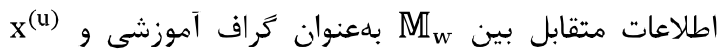

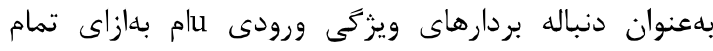
ورودىها است كه بلصورت زير تعريف مىشود:

$$
\begin{aligned}
& \mathcal{F}_{\mathrm{MMI}}=\sum_{\mathrm{u}=1}^{\mathrm{U}} \mathrm{I}\left(\mathrm{x}^{(\mathrm{u})}, \mathbb{M}_{\mathrm{w}^{(\mathrm{u})}}\right)= \\
& \sum_{\mathrm{u}=1}^{\mathrm{U}} \log \frac{\mathrm{p}_{\lambda}\left(\mathrm{x}^{(\mathrm{u})} \mid \mathrm{MI}_{\mathrm{w}}(\mathrm{u})\right)}{\mathrm{p}_{\lambda}\left(\mathrm{x}^{(\mathrm{u})}\right)}
\end{aligned}
$$

كه در آن I تابع اطلاعات مشترك و U تعداد كل نمونههاى آموزشى است؛ بنابراين اين تابع هدف كه تابع هدف MMI ناميده مىشود، علاوهبراين كه در سطح دنباله است، برخلاف تابع هدف بيشينه-شباهت يك تابع هدف تمايزى نيز است. يك رويكرد تركيبى كه از اين تابع هدف بهره برده است - LF [27 MMI5

${ }^{1}$ Maximum Mutual Information

${ }^{2}$ State-level Minimum Bayes Risk

${ }^{3}$ Minimum Word Error

${ }^{4}$ Minimum Phone Error

${ }^{5}$ Lattice-Free Maximum Mutual Information 
كره نزنيم، دقت بهدست آمده تغيير جندانى نمى كند؛ زيرا

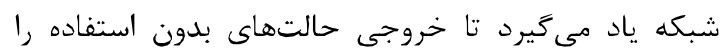
هميشه صفر توليد كند و اين باعث مى شود تا اين اين حالتها در هيج كدام از محاسبات تراف صورت و مخرج اثرى نداشته تواته باشند.

اين مقاله بهمك روشهاى يشيردازش و و نرمالسازى تصاوير كه در [38] ارائه شده است و همجين ائنين بهرهخيرى از رويكردهاى تركيبى LF-MMI و LF-MMI

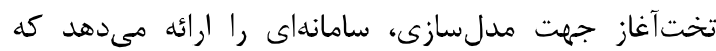

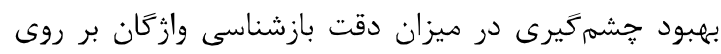

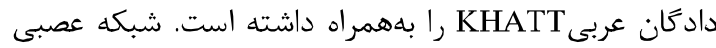
استفادهده در كليه آزمايشهاى أنجامشده در اين آناه مقاله

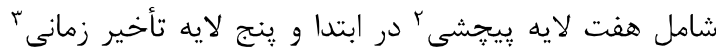

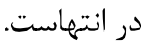

\section{ه- آنتايج و آزمايشها}

آزمايشها بر روى دادكان عربى KHATT انجام شده است. دادكان KHATT شامل تصاوير خطوط دستنوشته است كه دان از فرمهاى تكميل شده توسط هزار نويسنده استخراج شده

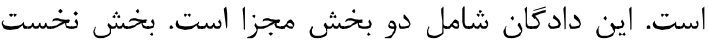
شامل جملاتى ثابتى است كه توسط تمام نويسندها نوان نوشته

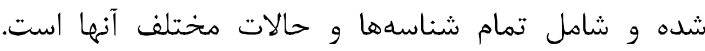

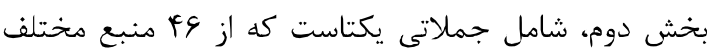
جمعآورى شده و براى هر نويسنده متفاوت است است اين دادFان درمجموع شامل

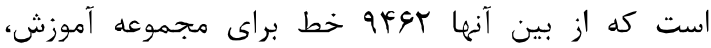

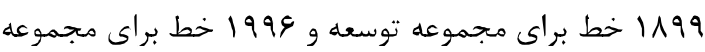

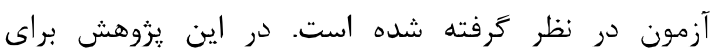
تقسيمبندى تصاوير به مجموعلهاى آموزش، توسعه و آزمون

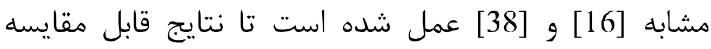
باشد. در انجام آزمايشها، از يك مدل زبانى 3-gram استفاده

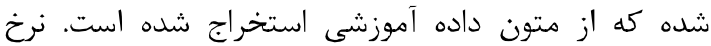

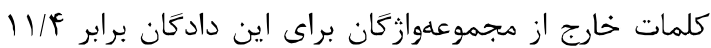

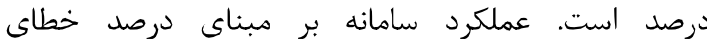

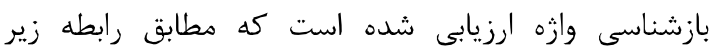

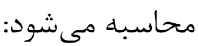

تعداد جايكزينى +تعداد حذف+تعداد درج تعداد كل كلمات * 100

${ }^{2}$ Convolutional

${ }^{3}$ Time Delay
بيجيدكى محاسبات در خود شبكه كاهش و همجنين

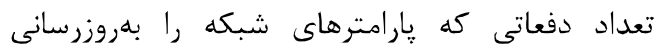
مى كنيم، كاهش يابد. كاهش نرخ قاب در خروجى باعث مىشود تا بهازاى هر سه قاب از ورودى، يكى بردار را ال از

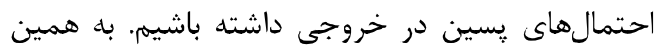

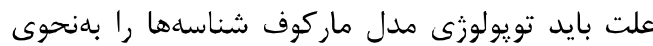
تغيير دهيم كه با يك كذر بتوان از هر شناسه عبور

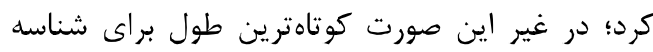

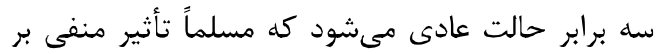

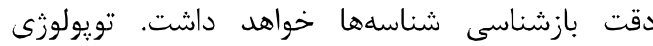

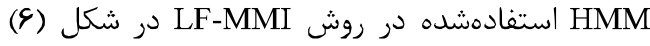

$$
\text { مشاهده مىشود. }
$$

ضعف عمدة مدل LF-MMI مشابه ساير رويكردهاى تركيبى اين است كه آموزش آن نياز به يك همترازى اوليه

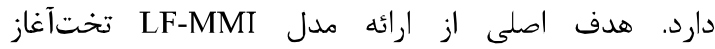
مرتفعردن اين مشكل است. به عبارتى اين روش در تلاش آر آله

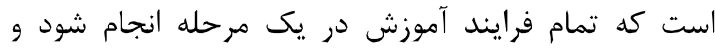

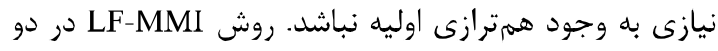

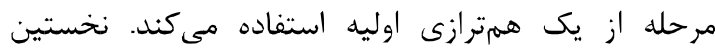

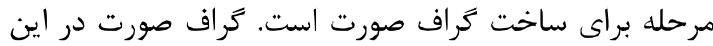
روش بر مبناى لاتيس ساختهشده بهوسيلة يك مدرل

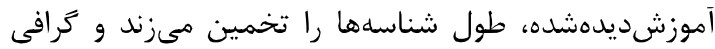

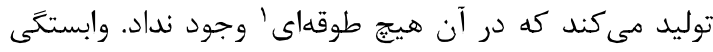
بعدى در مرحله آموزش درخت تصميهم بر مبناى همترازى دئ هئ

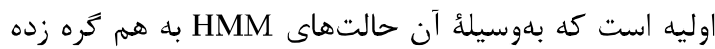
مىشوند. در روش LF-MMI تختآغاز براى حذف اين

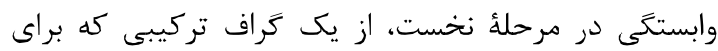
آموزش مدلهاى IIMM-GMM استفاده مىشود، بهعنوان كراف صورت استفاده مى كنيم. اين كراف هيج دحدوديتى

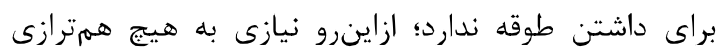

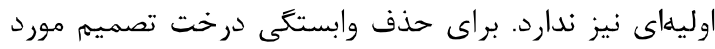

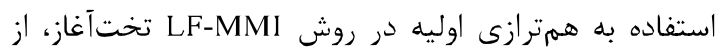
تمام تركيبهاى دوشناسهاى استفاده شده است؛ درواقع هيج

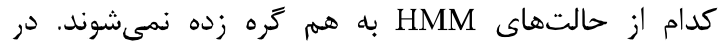

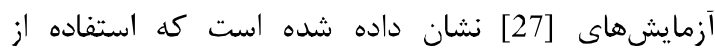

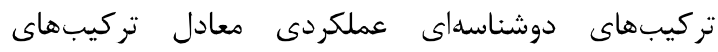
سهشناسهاى دارند؛ همجنين در آزمايشهاى اخير [14]

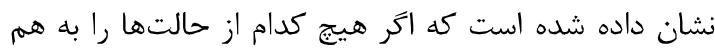

${ }^{1}$ Loop 
(جدول - r): درصد خطاى بازشناسى كلمه براى مجموعه توسعه و آزمون تعريف شده بر روى دادكان khatt بهازاى روشهاى مختلف

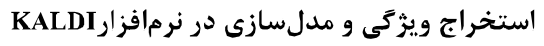

(Table-3): Word error rate of recognition on the test set and development set of KHATT data set for various feature extraction and modeling techniques in KALDI

\begin{tabular}{|c|c|c|c|c|c|}
\hline & \multirow[b]{3}{*}{ ويزگ ويى } & \multirow[b]{3}{*}{ واحد مدلسازى } & \multirow[b]{3}{*}{ مدلسازى } & \multirow{2}{*}{\multicolumn{2}{|c|}{ خطاى بازشناسى كلمه (.) }} \\
\hline \multirow[b]{2}{*}{ شماره } & & & & & \\
\hline & & & & توسعوعه & مجموعه \\
\hline 1 & Raw pixels + delta & Mono-Character & HMM-GMM & 103.87 & 103.41 \\
\hline 2 & Raw pixels + delta & Tri-Character & HMM-GMM & 78.05 & 76.46 \\
\hline 3 & Raw pixels + LDA + MLLT & Tri-Character & HMM-GMM & 56.08 & 54.14 \\
\hline 4 & $\begin{array}{c}\text { Raw pixcls + LDA - MLLT + } \\
\text { WAT }\end{array}$ & Tri-Character & HMM-GMM & 55.46 & 53.21 \\
\hline 5 & Raw pixels & Bi-Character & $\begin{array}{l}\text { HMM-DNN (LF- } \\
\text { MMI) }\end{array}$ & 29.31 & 27.96 \\
\hline
\end{tabular}

دارند، در اين مدل، ابتدا بهكمك مدل آموزش دادهشده در

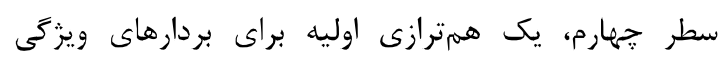

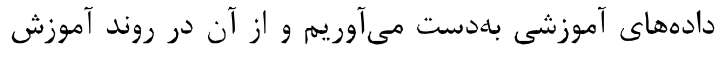
شبكه عصبى رويكرد تركيبى LF-MMI استفاده مي كن كنيم.

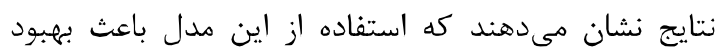
مطلق rD/TA درصدى در خطاى بازشناسى كلمات شده

است.

\section{1-ه- بر رسى تأثير همترازى شناسهاى اوليه}

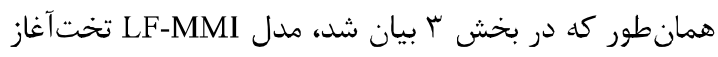

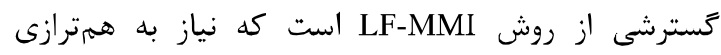

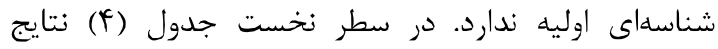

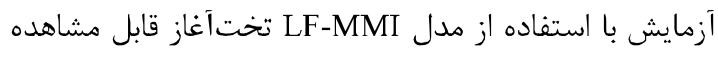

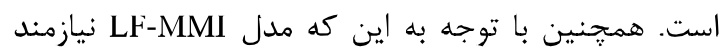

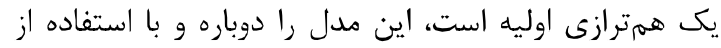

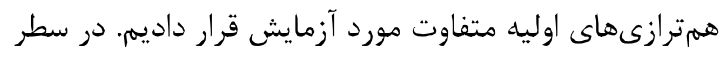

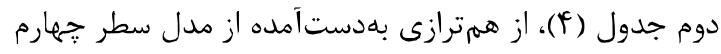

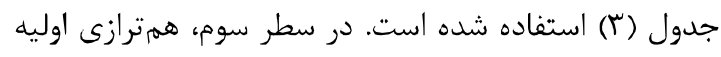

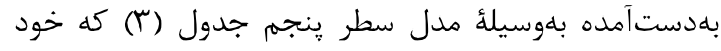

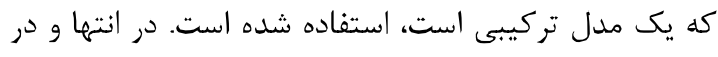

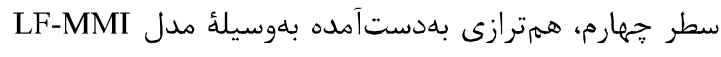

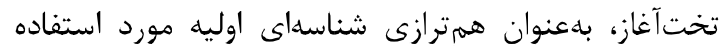

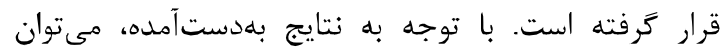

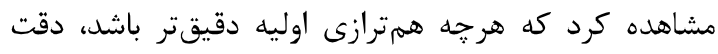

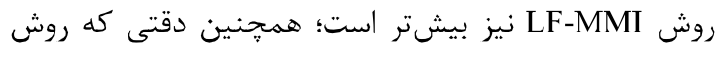

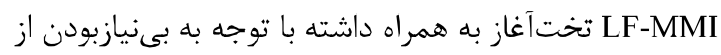
همترازى اوليه، دقت درخور توجهى است.
در جدول (r) نتايج بازشناسى بر روى مجموعه

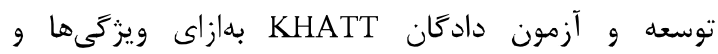

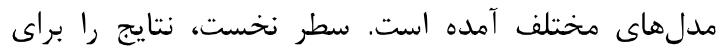

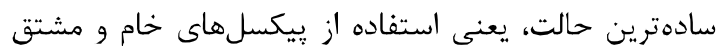

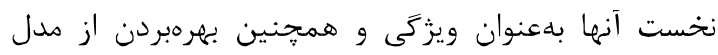

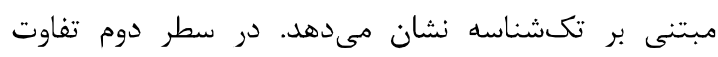
نسبت به سطر نخست تنها در روش مدل برسازى اتفاق افتاده

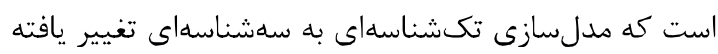

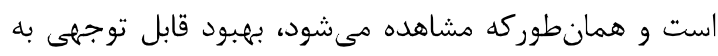

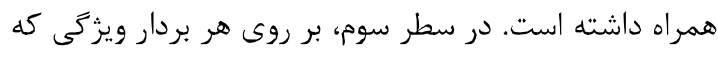

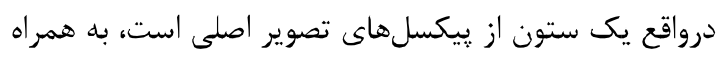

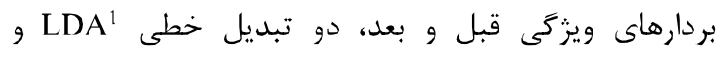

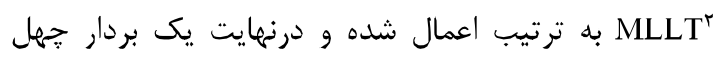

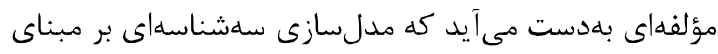

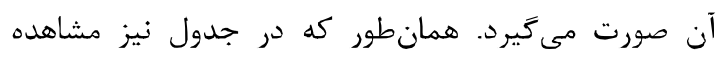

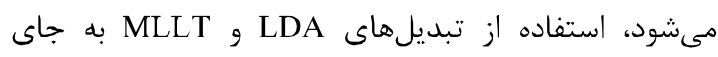

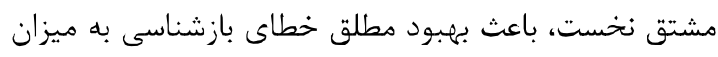

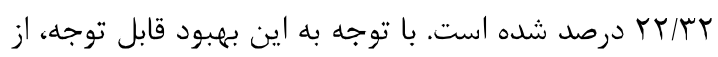

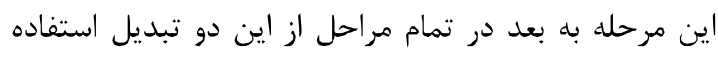

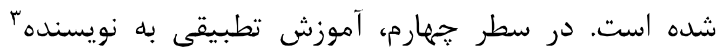

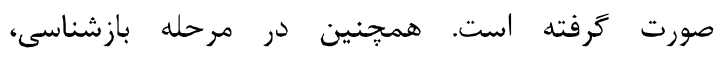
ويزگى هاى هر كوينده بهكمك روش

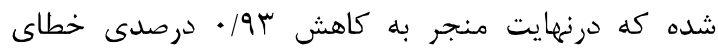

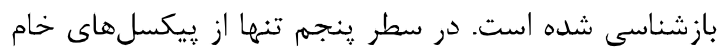

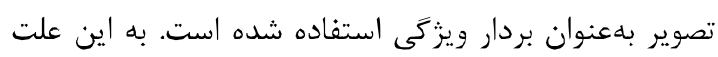

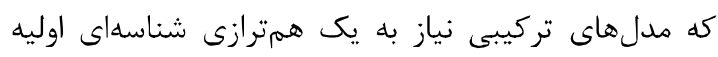

${ }^{1}$ Linear Discriminant Analysis

${ }^{2}$ Maximum Likelihood Linear Transform

${ }^{3}$ Writer Adaptive Training (WAT) 
مدل هاى زبانى مختلف بهوسيله مدل LF-MMI با همترازى

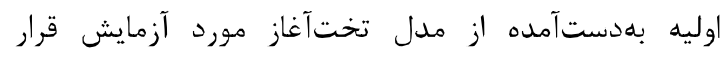
كرفتند. اين مدلهاى شامل 2-gram و كدام بلوسيلة روشهاى هموارسازى مارى ney

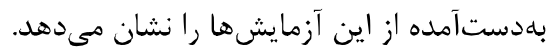
(جدول - (צ): تتايج بهدستآمده از انواع مدل زبانى و روشهاى مختلف هموارسازى

(Table-6): Results of various language model types and

\begin{tabular}{|c|c|c|c|}
\hline \multirow[t]{2}{*}{ مدل } & \multirow[t]{2}{*}{ هموارسازى } & \multicolumn{2}{|c|}{ خطاى بازشناسى كلمه } \\
\hline & & توسعه & آزمون \\
\hline 2-gram & Good-Turing & 25.20 & 24.00 \\
\hline 2-gram & Kneser-Ney & 24.57 & 23.19 \\
\hline 2-gram & MaxEnt & 24.96 & 23.68 \\
\hline 3-gram & Good-Turing & 25.34 & 24.14 \\
\hline 3-gram & Kneser-Ney & 24.88 & 23.52 \\
\hline 3-gram & MaxEnt & 24.60 & 23.18 \\
\hline
\end{tabular}

همانطور كه در جدول مشاهده مىشود، استفاده از مدل زبانى 2ram باعث كاهش نرخ خطا شده است. اين

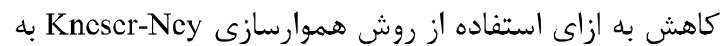

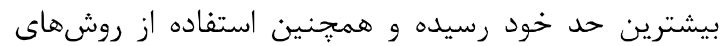

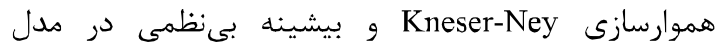
3-gram نيز باعث كاهش نرخ خطا شده است. در مدل

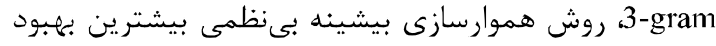

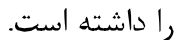

\section{د - F- مقايسه نتايج با ساير يزوهشها}

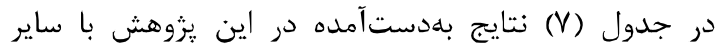

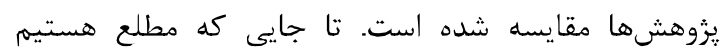
بهترين دقت بر روى دادكان خط با استفاده از مدل زبانى التهائ

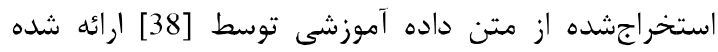

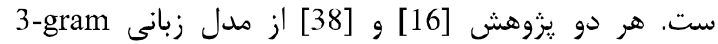

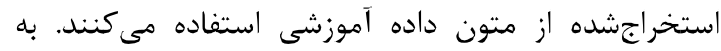

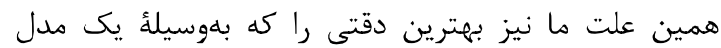

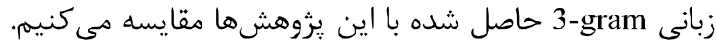

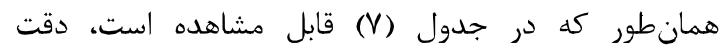

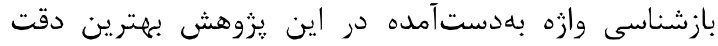
كزارششده را به ميزان ك/T/ V/ درصد مطلق بهبود بخشيده

${ }^{8}$ Maximum Entropy
(جدول - F): نتايج بهدست آمده از دو همرترازى اوليه متفاوت

(Table-4): Results of two different initial alignments

\begin{tabular}{|c|c|c|c|}
\hline \multirow[t]{2}{*}{ مدلسازى } & \multirow[t]{2}{*}{ همترازى اوليه } & \multicolumn{2}{|c|}{ خطاى بازشناسى } \\
\hline & & توسعه & آزمون \\
\hline $\begin{array}{l}\text { HMM-DNN (Flatstart } \\
\text { LF-MMI) }\end{array}$ & - & 28.87 & 26.83 \\
\hline $\begin{array}{c}\text { HMM-DNN (LF- } \\
\text { MMI) }\end{array}$ & HMM-GMM & 29.31 & 27.96 \\
\hline $\begin{array}{l}\text { HMM-DNN (LF- } \\
\text { MMI) }\end{array}$ & $\begin{array}{l}\text { HMM-DNN (LF- } \\
\text { MMI) }\end{array}$ & 27.66 & 26.26 \\
\hline $\begin{array}{c}\text { IIMM-DNN (LF- } \\
\text { MMI) }\end{array}$ & $\begin{array}{l}\text { HMM-DNN } \\
\text { (Flatstart LF- } \\
\text { MMI) }\end{array}$ & 26.21 & 25.32 \\
\hline
\end{tabular}

\section{ץ-ه- بررسى اثر افزايش داده'}

جهت بررسى اثر افزايش داده بر نرخ خطاى بازشناسى كلمه،

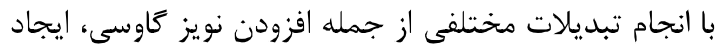

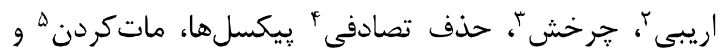

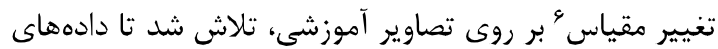

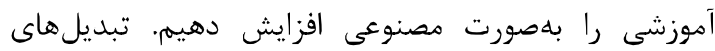

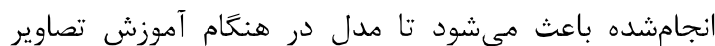

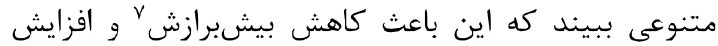

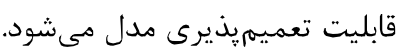

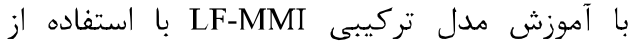

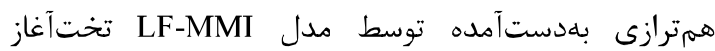
بهعنوان همترازى اوليه، بر روى دادههاى آموزشى افزايش

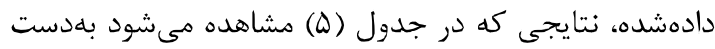
آهد. نتايج نشان مى دهند كه نرخ خطاى بازشناسى كلمه بر بر

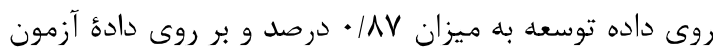

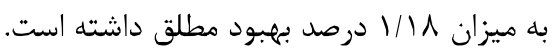

(جدول-ه)): نتايج بهدست آمده از آموزش مدل بر روى داده آموزشى افزايش يافته

(Table-5): Results of model training using augmented training data

\begin{tabular}{|c|c|c|}
\hline \multirow{2}{*}{ 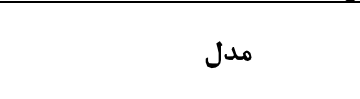 } & \multicolumn{2}{|c|}{ نرخ خطاى وازه (٪) } \\
\hline & توسعه & آزمون \\
\hline LF-MMI (without augmentation) & 26.21 & 25.32 \\
\hline LF-MMI (with augmentation) & 25.34 & 24.14 \\
\hline
\end{tabular}

$$
\text { ب- - ب- برسي اثر مدل زبانى }
$$

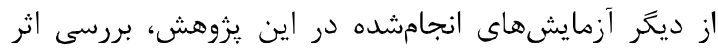
انواع مختلف مدل زبانى بر روى نتايج بهدستآمده است.

${ }^{1}$ Data Augmentation

${ }^{2}$ Skewing

${ }^{3}$ Rotating

${ }^{4}$ Dropout

${ }^{5}$ Blurring

${ }^{6}$ Scaling

${ }^{7}$ Over-fitting 


\section{7- References}

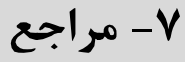

[1] R. Ahmad, S. Naz, M. Z. Afzal, S. F. Rashid, M. Liwicki, A. Dengel, "KHATT: A Deep Learning Benchmark on Arabic Script.", In 2017 14th IAPR International Conference on Document Analysis and Recognition (ICDAR), pp. 10-14, 2017.

[2] R. Al-Hajj, C. Mokbel, C. Mokbel, L. LikformanSulem and L. Likforman-Sulem, "Combination of HMM-Based Classifiers for the Recognition of Arabic Handwritten Words", Ninth International Conference on Document Analysis and Recognition (ICDAR 2007) Vol 2, 2007.

[3] J. AlKhatecb, J. Ren, J. Jiang and H. AlMuhtaseb, "Offline handwritten Arabic cursive text recognition using Hidden Markov Models and re-ranking", Pattern Recognition Letters, vol. 32, no. 8, pp. 1081-1088, 2011.

[4] L. Bahl, P. Brown, P. de Souza and R. Mercer, "Maximum mutual information estimation of hidden Markov model parameters for speech recognition", in International Conference on Acoustics, Speech, and Signal Processing, vol. 11, pp. 49-52, 1986.

[5] A. M. Bidgoli, M. Sarhadi, "IAUT/PHCN: Islamic Azad University of Tehran/Persian handwritten city names, a very large database of handwritten Persian word.", 11th International Conference on Frontiers in Handwriting Recognition, pp. 192197, 2008.

[6] A. Broumandnia, J. Shanbehzadeh and M. Rezakhah Varnoosfaderani, "Persian/arabic handwritten word recognition using M-band packet wavelet transform", Image and Vision Computing, vol. 26, no. 6, pp. 829-842, 2008.

[7] G. E. Dahl, D. Yu, L. Deng, and A. Acero, "Context-dependent pre-trained deep neural networks for large- vocabulary speech recognition," IEEE Transactions on Audio, Speech, and Language Processing, vol. 20, no. 1, pp. 30-42, 2012.

[8] M. Dehghan, K. Facz, M. Ahmadi and M. Shridhar, "Unconstrained Farsi handwritten word recognition using fuzzy vector quantization and hidden Markov models", Pattern Recognition Letters, vol. 22, no. 2, pp. 209-214, 2001.

[9] M. Dehghan, K. Facz, M. Ahmadi, M. Shridhar, "Handwritten Farsi (Arabic) word recognition: a holistic approach using discrete HMM," Pattern Recognition, vol. 34, no. 5, pp. 1057-1065, 2001.

[10] R. Duda and P. Hart, "Use of the Hough transformation to detect lines and curves in pictures", Communications of the ACM, vol. 15, no. 1, pp. 11-15, 1972.

[11] A. Elbaati, H. Boubaker, M. Kherallah, A. Ennaji, H. Abed and A. Alimi, "Arabic Handwriting Recognition Using Restored Stroke
(جدول -V): مقايسه نتايج بهدست آمده با ساير نتايج گزارششده

$$
\text { بر روى دادگان KHATT }
$$

(Table-7): Comparison of our results with other reported results on KHATT dataset

\begin{tabular}{|c|c|c|}
\hline \multirow{2}{*}{ يزووهش } & \multicolumn{2}{|c|}{ نرخ خطاى وارهه (\%) } \\
\hline & توسعه & آزمون \\
\hline Hamdani et al. [16] & 33.60 & 34.10 \\
\hline QCRI [38] & 29.40 & 30.50 \\
\hline Jemni et al. [17] & 31.60 & 29.44 \\
\hline يثوهش جارى & 24.60 & 23.18 \\
\hline
\end{tabular}

\section{و- جمع بندى}

در اين مقاله بعد از مرورى اجمالى بر روى يزوهشهاى صورت

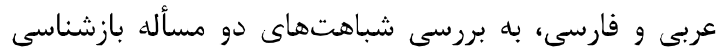

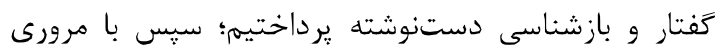

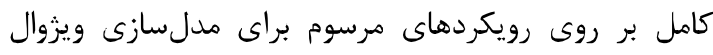

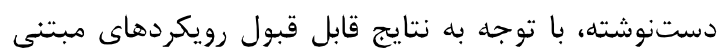
بر HMM-DNN در حوزه بازشناسى كَفتار و همجنين

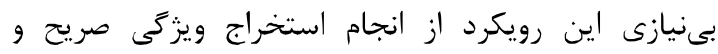

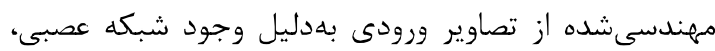
اين رويكرد را براى آزمايش بر روى دادَّان

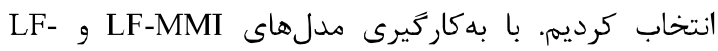

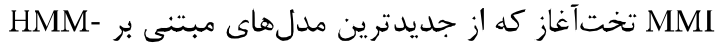

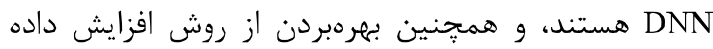
موفق به بهبود نرخ خطاى كلمه بر روى اين دادكان شديه. بهترين نرخ خطاى وازه بر روى مجموعه توسعه برابر با بـان .

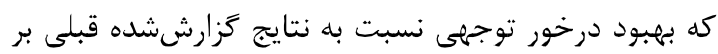

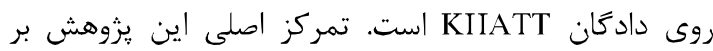
روى بهكارگيرى مدلهاى مرسوم در حوزه بازشناسى كفتار براى حل مسأله بازشناسى دستنوشته عربى بوده است.

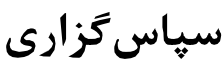

نويسندكان مقالد برخود لازم مى انداند از همكارى و حمايت آقاى دنيل يووى يزوهش (CLSP)

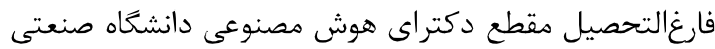
شريف بهخاطر راهنمايىهاى بىدريغشان و فهيمر عمادالدين مادي

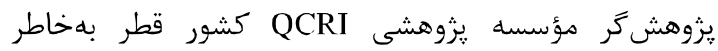

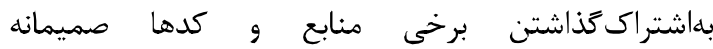
سياس كزارى كند. 
of Farsi handwritten city names." In International Conference on Frontiers in Handwriting Recognition. 2008.

[23] S. Mozaffari, K. Faez, F. Faradji, M. Ziaratban, S. M. Golzan, "A comprehensive isolated Farsi/Arabic character database for handwritten OCR research," In Tenth International Workshop on Frontiers in Handwriting Recognition, Suvisoft, 2006.

[24] S. Mozaffari, K. Faez and M. Ziaratban, "Structural decomposition and statistical description of Farsi/Arabic handwritten numeric characters", Eighth International Conference on Document Analysis and Recognition (ICDAR'05), 2005.

[25] M. Pechwitz, S. S. Maddouri, V. Märgner, N. Ellouze, H. Amiri. "IFN/ENIT-database of handwritten Arabic words," In Proc. of CIFED, vol. 2, pp. 127-136. 2002.

[26] D. Povey, A. Ghoshal, G. Boulianne, L. Burget, O. Glembek, N. Gocl, M. Hannemann, P. Motlicek, Y. Qian, P. Schwarz, J. Silovsky, G. Stemmer, K. Vesely, "The Kaldi speech recognition toolkit," In IEEE 2011 workshop on automatic speech recognition and understanding, IEEE Signal Processing Society, 2011.

[27] D. Povey, V. Peddinti, D. Galvez, P. Ghahrmani, V. Manohar, $\mathrm{X}$. $\mathrm{Na}, \mathrm{Y}$. Wang, and $\mathrm{S}$. Khudanpur, "Purely sequence-trained neural networks for asr based on lattice-free $\mathrm{mmi}$," in Interspecch, 2016.

[28] D. Povey and P. C. Woodland, "Minimum phone error and i-smoothing for improved discriminative train- ing," in IEEE International Conference on Acoustics, Speech, and Signal Processing (ICASSP, vol. 1. IEEE, pp. I-105, 2002.

[29] D. Rybach, S. Hahn, P. Lehnen, D. Nolden, M. Sundermeyer, Z. Tüske, S. Wiesler, R. Schlüter, $\mathrm{H}$ Ney, "Rasr-the rwth aachen university open source speech recognition toolkit," In Proc. IEEE Automatic Speech Recognition and Understanding Workshop. 2011.

[30] R. Sabzi, Z. Fotoohinya, A. Khalili, S. Golzari, Z. Salkhorde, S. Behravesh, S. Akbarpour, "Recognizing Persian handwritten words using deep convolutional networks," in Artificial Intelligence and Signal Processing Conference (AISP), pp. 85-90, 2017.

[31] J. Sadri, C. Y. Suen, and T. D. Bui, "Application of support vector machines for recognition of handwritten Arabic/Persian digits," In Proceedings of Second Iranian Conference on Machine Vision and Image Processing, vol. 1, pp. 300-307. 2003.
Chronology", 2009 10th International Conference on Document Analysis and Recognition, 2009.

[12] V. Goel and W. Byrne, "Minimum Bayes-risk automatic speech recognition", Computer Speech \& Language, vol. 14, no. 2, pp. 115-135, 2000.

[13] A. Graves, S. Fernández, F. Gomez and J. Schmidhuber, "Connectionist temporal classification: labelling unsegmented sequence data with recurrent neural networks," In Proceedings of the 23rd international conference on Machine learning, pp. 369-376, 2006.

[14] H. Hadian, H. Sameti, D. Povey and S. Khudanpur, "Flat-Start Single-Stage Discriminatively Trained HMM-Based Models for ASR", IEEE/ACM Transactions on Audio, Speech, and Language Processing, vol. 26, no. 11, pp. 1949-1961, 2018.

[15] P. Haghighi, N. Nobile, C. He and C. Suen, "A New Large-Scale Multi-purpose Handwritten Farsi Database", Lecture Notes in Computer Science, pp. 278-286, 2009.

[16] M. Hamdani, A. Mousa and H. Ney, "Open Vocabulary Arabic Handwriting Recognition Using Morphological Decomposition", 2013 12th International Conference on Document Analysis and Recognition, 2013.

[17] S. K. Jemni, Y. Kessentini, S. Kanoun, J. Ogier, "Offline Arabic Handwriting Recognition Using BLSTMs Combination.", In 2018 13th IAPR International Workshop on Document Analysis Systems (DAS), pp. 31-36, 2018.

[18] S. Khorashadizadeh, A. Latif, "Arabic/Farsi Handwritten Digit Recognition usin Histogra of Oriented Gradient and Chain Code Histogram", International Arab Journal of Information Technology (IAJIT), vol. 13, no. 4, 2016.

[19] H. Khosravi, E. Kabir, "Introducing a very large dataset of handwritten Farsi digits and a study on their varieties.", Pattern recognition letters, vol. 28, no. 10, pp. 1133-1141. 2007.

[20] D. Lee, S. Ismael, S. Grimes, D. Doermann, S. Strassel, Z. Song, "MADCAT Phase 1 Training Set", LDC2012T15. DVD. Philadelphia: Linguistic Data Consortium, 2012.

[21] S. A. Mahmoud, I. Ahmad, M. Alshayeb, W. G. Al-Khatib, M. T. Parvez, G. A. Fink, V. Margner, H. E. Abed, "KHATT: Arabic offline handwritten text database," In 2012 International Conference on Frontiers in Handwriting Recognition (ICFHR 2012), pp. 449-454, 2012.

[22] S. Mozaffari, H. E. Abed, V. Märgner, K. Faez, A. Amirshahi. "IfN/Farsi-Database: a database 


$$
\begin{aligned}
& \text { كراديان تصوير" مجله علمى و يزوهشى يردازش علائم } \\
& \text { و دادهol }
\end{aligned}
$$

[43] E. Bayesteh Tashk, A. Ahmadifard and H. khosravi, "A two step method for offline handwritten Farsi word recognition using adaptive division of gradient image", JSDP, Vol.12 (3), pp.15-29, 2015.

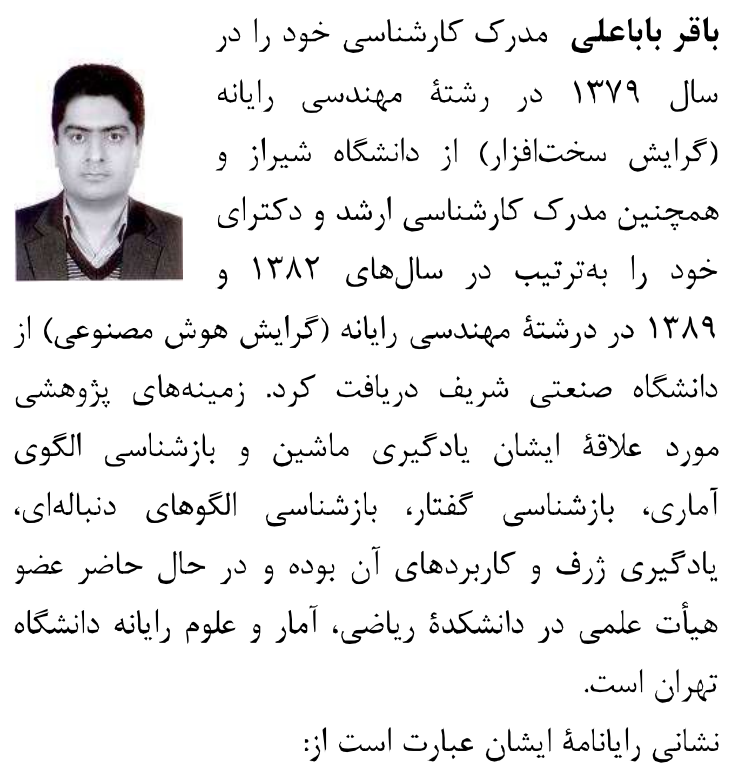

babaali@ut.ac.ir

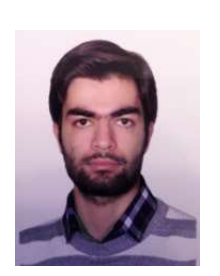

بابك ركابدار مدرى كارشناسى خود را

در سال هوبا در رشتهُ علوم رايانه از

دانشگاه اميركبير دريافت كرد. همجنين لهن

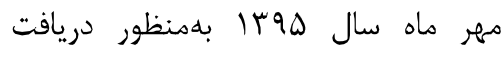
مدرك كارشناسى ارشد (ترايش هوش مصنوعى) وارد دانشگاه تهران شد. زمينههاى يزوهشى مورد

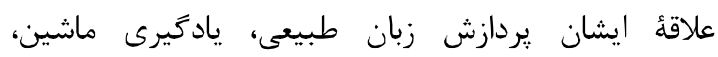
بازشناسى دستنوشته و يادگيرى زرف است. نشانى رايانامةٔ ايشان عبارت است ازيتان

Babak.rekabdar@ut.ac.ir
[32] J. Sadri, M. R. Yeganehzad, J. Saghi, "A novel comprehensive database for offline Persian handwriting recognition.", Pattern Recognition, vol. 60, pp. 378-393, 2016.

[33] R. Safabaksh, A. Ghanbarian and G. Ghiasi, "HaFT: A handwritten Farsi text database", 2013 8th Iranian Conference on Machine Vision and Image Processing (MVIP), 2013.

[34] H. Sajedi, "Handwriting recognition of digits, signs, and numerical strings in Persian", Computers \& Electrical Engineering, vol. 49, pp. 52-65, 2016.

[35] H. Sak, O. Vinyals, G. Heigold, A. Senior, E. McDermott, R. Monga, and M. Mao, "Sequence discriminative distributed training of long shortterm memory recurrent neural networks," in Interspeech, 2014.

[36] H. Soltanzadeh, M Rahmati, "Recognition of Persian handwritten digits using image profiles of multiple orientations," Pattern Recognition Letters, vol. 25, no. 14, pp. 1569-1576, 2004.

[37] F. Stahlberg and S. Vogel, "Detecting dense foreground stripes in Arabic handwriting for accurate baseline positioning", 2015 13th International Conference on Document Analysis and Recognition (ICDAR), 2015.

[38] F. Stahlberg and S. Vogel, "The QCRI Recognition System for Handwritten Arabic", Image Analysis and Processing, pp. 276-286, 2015.

[39] P. Voigtlaender, P. Doetsch, S. Wiesler, R. Schlüter, and H. Ney, "Sequence-discriminative training of re- current neural networks," in IEEE International Conference on Acoustics, Speech and Signal Processing (ICASSP). IEEE, pp. 2100-2104, 2015.

[40] K. Veselỳ, A. Ghoshal, L. Burget, and D. Povey, "Sequence-discriminative training of deep neural net- works," in INTERSPEECH, pp. 2345-2349, 2013.

[41] S. Young, G. Evermann, D. Kershaw, G. Moore, J. Odell, D. Ollason, D. Povey, V. Valtchev, P. Woodland, The HTK Book (for version 3.4). Cambridge Univ. Eng. Dept., 2009.

[42] M. Ziaratban, K. Faez and F. Bagheri, "FHT: An Unconstraint Farsi Handwritten Text Database", 2009 10th International Conference on Document Analysis and Recognition, pp. 281285, 2009.

$$
\begin{aligned}
& \text { [43] بايسته، تاشك الهام، احمدى فرد، عليرضا و خسروى، } \\
& \text { حسين "يك روش دو مرحلهاى براى بازشناسى كلمات }
\end{aligned}
$$

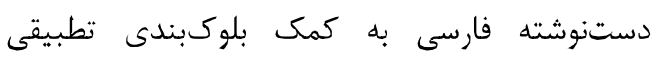

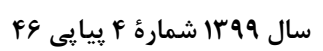

